\title{
A DINÂMICA DOS RECURSOS FISCAIS COM AS POLÍTICAS DE FUNDOS CONTÁBEIS PARA O FINANCIAMENTO DA EDUCAÇÃO NO BRASIL
}

(1998-2010)

\author{
Fábio Luciano Oliveira Costa ${ }^{1}$ \\ Universidade de São Paulo (USP)
}

\section{RESUMO}

O objetivo principal deste artigo é investigar a dinâmica fiscal das políticas de Fundos contábeis para o financiamento da educação no Brasil, Fundef e Fundeb, entre os anos de 1998 a 2010. Para tanto, faz-se uma exposição geral associada às características dos Fundos, por meio da análise de documentos legais e da literatura pertinente ao tema, como no caso de livros, teses, dissertações e artigos publicados em periódicos especializados. Os dados apresentados foram coletados, sobretudo no endereço eletrônico de instituições públicas, a exemplo do FNDE e da STN, além da literatura pesquisada. Os Fundos trouxeram novos recursos, primeiro para o ensino fundamental público, depois para toda a educação básica pública e parte da privada, tendo como principal fonte o ICMS. No entanto, ainda permaneceram grandes desigualdades interestaduais no financiamento da educação básica e sua universalização, fora o fato de estar relativamente distante a associação entre recursos educacionais e qualidade no processo de ensino e aprendizagem, o que necessariamente leva à inclusão de novas fontes para efetivar melhorias substantivas para essa política pública em todo o território brasileiro.

Palavras-chave: Educação, Fundef, Fundeb, Recursos Fiscais.

\section{DYNAMICS OF FUNDS TO FISCAL POLICIES ACCOUNTING OF FUNDS FOR THE FINANCING OF EDUCATION IN BRAZIL}

(1997-2010)

\begin{abstract}
The main objective of this paper is to investigate the dynamics of fiscal policy funds accounting for the financing of education in Brazil, and Fundef Fundeb, between the years 1998 to 2010. Therefore, it is usually associated with exposure to the characteristics of the Funds, through the analysis of legal documents and literature relevant to the topic, as in the case of books, theses, dissertations and articles in professional journals. The data presented were collected, especially in the email address from public institutions, such as the ENDF and the STN, in addition to the literature. Funds brought new features, for the first public elementary school after basic education for all public and part private, with the primary source of GST. However, there still remained large interstate inequalities in the financing of basic education and its universalization, apart from the fact that it is relatively distant from the association between educational resources and quality in teaching and learning, which necessarily leads to the inclusion of new sources to effect improvements for that substantive public policy throughout the Brazilian territory.
\end{abstract}

Keywords: Education, Fundef, Fundeb, Tax Appeals. 


\section{Introdução}

A insuficiente clareza na definição das responsabilidades dos entes federados para com os níveis de ensino, que não estabeleceu relação entre os recursos fiscais e a oferta educacional, - tendo sido mais bem esclarecida com a Lei de Diretrizes e Bases (LDB), a Emenda Constitucional (EC) $\mathrm{n}^{\circ} 14$ e a Lei $\mathrm{n}^{\circ}$ 9.424, todas de 1996 -, acabaram por desencadear a ineficiência dos gastos, o desvio dos recursos e a falta de transparência na gestão financeira das políticas educacionais.

No âmbito do mesmo estado, a redistribuição dos recursos passou a ocorrer em função do número de matrículas, ao menos para o ensino fundamental público, obtendo comportamentos semelhantes e pré-fixados pelas determinações legais para o extenso número de municípios. Os governos municipais tiveram ampliação importante após a promulgação da Constituição Federal (CF) de 1988 e na primeira metade da década de 1990, contribuindo para reduzir o poder institucional do governo federal de influenciar a educação municipal.

O objetivo principal deste artigo é investigar a dinâmica fiscal das políticas de Fundos contábeis para o financiamento da educação no Brasil, com o Fundo de Manutenção e Desenvolvimento do Ensino Fundamental e de Valorização do Magistério (Fundef) e o Fundo de Manutenção e Desenvolvimento da Educação Básica e de Valorização dos Profissionais da Educação (Fundeb), entre os anos de 1998 a 2010.

Para viabilizar a temática central, faz-se uma exposição geral associada às características dos Fundos, por meio da análise de documentos legais e da literatura pertinente ao tema, como no caso de livros, teses, dissertações e artigos publicados em periódicos especializados.

Os dados apresentados foram coletados, sobretudo no endereço eletrônico de instituições públicas, a exemplo do Fundo Nacional de Desenvolvimento da Educação (FNDE) e da Secretaria do Tesouro Nacional (STN), bem como na literatura pesquisada.

Além desta introdução, o texto conta com mais cinco partes. Na primeira, trata-se das mudanças que o novo ordenamento legal, também associado ao Fundef, inseriu para o financiamento do ensino fundamental público para as redes estaduais e municipais de ensino, as quais apresentavam elevadas diferenças, muitas vezes no mesmo município, entre municípios de um mesmo estado e entre os próprios estados da federação.

Para a segunda, analisam-se os gastos no Fundef (1998-2006), tendo em conta suas principais fontes de financiamento, ou seja, a receita de alguns impostos vinculados à Manutenção e Desenvolvimento do Ensino (MDE) fundamental público e a complementação da União, conforme os dispositivos legais, além das contribuições de estados e municípios durante o período em que esteve em vigência.

$\mathrm{Na}$ terceira, apresentam-se as principais mudanças introduzidas pelos ordenamentos legais que também originaram o Fundeb, o qual passou a financiar toda a educação básica pública e parte da educação privada, depois de finalizado o prazo de vigência do Fundef. Assim, diversos pontos relacionados à organização e operacionalização dos Fundos foram delegados para lei posterior, primeiro estabelecidos pela Medida Provisória (MP) $\mathrm{n}^{\circ}$ 339/2006, e depois pela Lei $n^{\circ} 11.494 / 2007$.

A quarta parte buscou discutir a dinâmica fiscal para as principais fontes de recursos do Fundeb, no período de 2007 a 2010, assim como os gastos dos governos subnacionais no período. De forma geral, o Fundo trouxe poucos novos recursos para a educação básica, mantendo a mesma lógica do Fundef.

Por fim, as considerações finais chamam a atenção para o fato de que, mesmo com as melhorias para o financiamento da educação efetivadas pelas políticas de Fundos 
contábeis, ainda se encontra razoavelmente distante a qualidade na educação básica brasileira.

\section{As mudanças no financiamento do ensino fundamental (público) com o Fundef}

O Fundef se constituiu no principal instrumento para viabilizar mudanças no financiamento do ensino fundamental, no intuito de alcançar, entre outros, sua universalização para o público de 7 a 14 anos, bem como a municipalização para esse nível de ensino. As modificações introduzidas com o Fundo também levaram a alterações em outros níveis e modalidades da educação básica pública.

Para viabilizar as novas propostas relacionadas ao seu financiamento, no contexto das reformas das instituições estatais, o Ministério da Educação (MEC) encarregou o então secretário-executivo do FNDE, Barjas Negri, a realizar estudos sobre a arrecadação dos impostos e os recursos disponíveis para os sistemas de ensino dos entes federados.

Os resultados apontaram grandes diferenças no financiamento do ensino fundamental (público) nas redes estaduais e municipais, que poderiam ocorrer no contexto de um mesmo município, entre os municípios de um mesmo estado e entre os estados, no âmbito da federação (MONLEVADE; FERREIRA, 1997).

Além disso, houve a necessidade de intervir nas irregularidades associadas ao descumprimento do Ato das Disposições Constitucionais Transitórias (ADCT) (art. 60)², por parte da União, a qual não vinha aplicando $50 \%$ dos recursos vinculados à educação para acabar com o analfabetismo e universalizar o ensino obrigatório.

De acordo com Oliveira (2001), a União computava os 50\% a serem investidos no ensino fundamental como resultado da média da aplicação dos diferentes entes federados, e não como uma responsabilidade associada a cada um deles. Como os estados e municípios aplicavam nesse nível de ensino, percentuais acima do mínimo estabelecido (respectivamente de 68,4\% e 59\%, para o ano de 1995), acabaram por compensar a irregular aplicação da União (22,9\%), denunciada pelo Tribunal de Contas da União (TCU) quanto à inconstitucionalidade dos gastos educacionais.

Para Monlevade e Ferreira (1997), os principais motivos para o descumprimento do art. 60 do ADCT, por parte da União, estiveram relacionados ao financiamento do sistema federal de ensino, pagamento de inativos e, desde 1994, à retirada de $20 \%$ dos recursos educacionais com o Fundo Social de Emergência (FSE), percentual esse necessário para amenizar os déficits das contas públicas e permitir o pagamento dos compromissos financeiros nacionais e internacionais. Assim, Fernando Henrique Cardoso (FHC) teria sido mais "coerente" (IDEM, IBIDEM, p. 22), quando propôs mudanças no texto constitucional.

Nesse sentido, Paulo de Sena Martins apontou que autores na área jurídica, como Rocha (2001) e Silva (2009) consideraram incoerência emendar disposições transitórias, pois tenderia a perpetuar o que foi colocado como algo que deveria ser modificado; já para outros autores, como Ferraz (1999), seria permitido emendar as disposições transitórias, desde que atendidos os limites relacionados ao poder constituinte em questão, às cláusulas pétreas, bem como à:

[...] compatibilidade da modificação com a finalidade do regramento do ADCT (estabelecer exceções precárias e transitórias às regras permanentes). Caso contrário, haveria inconstitucionalidade por "desvio de finalidade". Assim, há que se avaliar se pode ser considerado como transitório o caráter do Fundef (e do Fundeb) (MARTINS, 2009, p. 132) ${ }^{3}$. 
A proposição de um Fundo contábil para o financiamento do ensino fundamental foi feita com a apresentação pelo Executivo federal da Proposta de Emenda Constitucional (PEC) $n^{\circ}$ 233/1995. Durante o processo de tramitação da Proposta, alguns deputados e senadores do Partido dos Trabalhadores (PT) acrescentaram emendas associadas à criação de um Fundo para toda a educação básica pública, as quais não foram levadas adiante naquele período (OLIVEIRA, 2009).

Atenuadas as divergências entre a situação governamental e a oposição, bem como as pressões exercidas por entidades como a União Nacional dos Dirigentes Municipais de Educação (UNDIME) e o Conselho Nacional de Secretários de Educação (CONSED), que levaram a ajustes na Proposta, mas mantendo sua essência inicial, em menos de um ano, a maioria parlamentar no Congresso Nacional obtida pelo Executivo, proporcionada pela coalizão governamental, aprovou, em setembro de 1996, a EC $\mathrm{n}^{\circ} 14$. Assim, foram modificados os arts. 34, 208, 211 e 212 da CF/1988 e se deu nova redação ao art. 60 do ADCT.

A aprovação da EC n ${ }^{\circ}$ 14/1996 determinou que os estados, o Distrito Federal e os municípios destinassem ao ensino fundamental público, pelo período de 10 anos, $60 \%$ dos $25 \%$ referentes aos recursos resultantes da arrecadação de impostos vinculados à MDE (art. 60, do ADCT), aplicados de acordo com o que foi definido nos arts. 70 e 71 da LDB/1996.

Para cada estado e seus municípios, a distribuição de responsabilidades e recursos deveria ser efetivada por meio do Fundef, tendo como parâmetro o número de matrículas no ensino fundamental público nas respectivas redes de ensino (art. 60, $\S \S 1^{\circ}$ e $2^{\circ}$, do ADCT), e fonte adicional de financiamento o salário-educação (dando nova redação ao art. $212, \S 5^{\circ}$, da $\mathrm{CF} / 1988$ ).

Por parte da União, os problemas de inconstitucionalidade na aplicação do percentual mínimo a ser investido no ensino fundamental público foram resolvidos com as modificações introduzidas pela $\mathrm{EC} \mathrm{n}^{\circ}$ 14/1996, mediante a redução de sua participação de, pelo menos 50\%, para no mínimo, o equivalente a $30 \%$ (art. $60, \S 6^{\circ}$, do ADCT).

O termo equivalente, segundo Pinto (1999), significou que esse percentual não precisaria ser necessariamente associado à receita de impostos. Nesse sentido, a União poderia acrescentar recursos do salário-educação, do Fundo de Amparo ao Trabalhador (FAT) e de outras contribuições sociais para atingir os $30 \%$ dos $18 \%$ constitucionalmente vinculados, retirando, assim, recursos da educação. Vale observar que, para os estados e municípios, o salário-educação permaneceu como fonte adicional de recursos.

Os gastos do governo federal para com esse nível de ensino passaram para 5,4\% e não mais $9 \%^{4}$ da arrecadação de seus impostos vinculados à erradicação do analfabetismo e MDE fundamental público, incluindo a complementação de recursos por parte da União, para o caso dos Fundos nos estados (Distrito Federal) que não alcançassem o mínimo definido nacionalmente $\left(\S 3^{\circ}\right)$.

A EC n ${ }^{\circ} 14 / 1996$, que clarificou as responsabilidades dos entes federados para com a educação e criou o Fundef, buscou por meio do Fundo, universalizar o ensino fundamental, mesmo sem a injeção de novos recursos e com a decrescente participação financeira da União, assim como regularizar o fluxo de repasses, evitando atrasos e até mesmo desvios.

Ainda, pretendeu diminuir as diferenças de investimento por aluno/ano no âmbito de um mesmo estado; valorizar o magistério, uma vez que o Fundef subvinculou $60 \%$ dos seus recursos para o pagamento de professores do ensino fundamental "em efetivo exercício no magistério" (art. 60, $\S 5^{\circ}$, do ADCT); além de tornar mais transparente e eficiente os critérios do sistema de partilha e das transferências legais, por meio de uma pequena reforma tributária (ARRETCHE, 2002). 
De acordo com a EC $n^{\circ} 14 / 1996$, no prazo de cinco anos, os entes federados, progressivamente deveriam garantir um valor por aluno que pudesse estabelecer um padrão mínimo de qualidade no ensino definido em todo o país (art. $60, \S 4^{\circ}$, do ADCT), o que não ocorreu, não só pelas questões financeiras, mas também pelo histórico déficit educacional no país que impede majoritariamente a formação de indivíduos críticos, tanto com relação ao ambiente ao qual estão inseridos quanto ao conjunto do sistema.

Ainda, determinou a disposição por Lei Complementar, da organização dos Fundos nos governos subnacionais, as formas de repartição proporcionais dos recursos, fiscalização, controle, bem como deveria apresentar a forma de cálculo do valor mínimo por aluno definido nacionalmente (art. 60, $\S 7^{\circ}$, do ADCT). Assim, o Fundef, criado pela EC $\mathrm{n}^{\circ}$ 14/1996, foi regulamentado pela Lei ${ }^{\circ}$ 9.424/1996, e pelo Decreto $n^{\circ} 2.264 / 1997$.

O Fundef, segundo a Lei ${ }^{\circ} 9.424 / 1996$, foi instituído no âmbito de cada estado e do Distrito Federal, constituindo-se em um Fundo de natureza contábil (art. $1^{\circ}$ ). Sob essa perspectiva, o Fundo impôs no país "a prática de realocação horizontal de recursos" (TORRES, 2003, p. 355), pois retirou verbas de alguns municípios para realocá-las em outros.

De acordo com a mesma lei, a implantação do Fundef ocorreu automaticamente a partir de janeiro de 1998, com contas únicas e específicas (art. $3^{\circ}$ ), no Banco do Brasil, em que o montante de cada Fundo estadual foi repartido no âmbito do próprio estado, proporcionalmente ao número de matrículas no ensino fundamental público (art. $2^{\circ}, \S 1^{\circ}$ ). No Distrito Federal, a unidade federada foi, ao mesmo tempo, provedora e receptora única dos recursos do Fundef.

Por não terem percebido com maior clareza a forma de redistribuição dos recursos estruturada pelo Fundef, os governos subnacionais tiveram o ano de 1997, como prazo de carência, antes de implantar definitivamente a vigência compulsória do Fundo.

A antecipação para a implantação do Fundo estadual ou distrital, conforme a Lei $\mathbf{n}^{\circ}$ 9.424/1996 poderia ser feita por meio de lei específica (art. $1^{\circ}$, $\S \S 4^{\circ}$ e $5^{\circ}$ ), no ano de 1997 , mediante a decisão das respectivas Assembléias Legislativas, o que ocorreu apenas para o estado do Pará, a partir de $1^{\circ}$ de julho, no intuito de obter assistência financeira por meio da complementação da União, em virtude dos escassos recursos para financiar o ensino fundamental público.

A composição do Fundef, de acordo com a Lei no 9.424/1996, correspondeu a 15\% da receita do Imposto sobre a Circulação de Mercadorias e Serviços (ICMS), do Fundo de Participação dos Estados (FPE), do Fundo de Participação dos Municípios (FPM), do Imposto sobre Produtos Industrializados (IPI-exportação) - proporcionalmente ao valor das exportações de bens industrializados -, da Lei Kandir (como ressarcimento pela desoneração do ICMS das exportações) (art. $1^{\circ}, \S \S 1^{\circ}$ e $2^{\circ}$ ), além da complementação da União, quando era o caso (art. $1^{\circ}, \S 3^{\circ}$; art. $6^{\circ}$ ).

Também compuseram recursos para o Fundo, os rendimentos adicionais financeiros provenientes de suas receitas, associadas ao ensino fundamental público. Se os valores mínimos dispostos legalmente não fossem aplicados na execução orçamentária anual, deveriam ser investidos no nível de ensino a que o Fundo se destinava, no exercício seguinte, acrescidos de correção monetária.

Segundo o Decreto $\mathrm{n}^{\circ}$ 2.264/1997, os recursos passaram a obedecer aos mesmos prazos das fontes primárias para a composição do Fundo, com fluxos semanais, decendiais e mensais (art. $2^{\circ}, \S 5^{\circ}$ ), que poderiam ser transferidos para outro banco público, desde que com conta vinculada ao Fundef, para atender às suas finalidades. Kolslinski (2000, p. 73) descreveu a periodicidade dos repasses, de acordo com as fontes de recursos para o Fundef: 


\begin{abstract}
A parcela de recursos do Fundo, originária do ICMS, é creditada semanalmente (periodicidade de repasses do ICMS), de acordo com o calendário de cada Estado [...] A parcela originária do FPE, FPM e IPIexp é creditada a cada decênio (sic) do mês, ou seja, dias 10,20 e 30 (periodicidade de repasses dessas transferências) [...] A parcela originária da Desoneração das Exportações (Lei Complementar $n^{\circ}$ 87/96), e a transferência relativa à complementação da União, são creditadas ao final de cada mês.
\end{abstract}

Vale destacar que os estados (Distrito Federal) e municípios, também deveriam aplicar no mínimo $15 \%$ dos demais impostos, aqui considerados como aqueles que não integravam o Fundo, na MDE fundamental público. Com isso, o Fundef desconsiderou os demais níveis, modalidades e tipos de estabelecimento de ensino da educação básica, que foram financiados por esses níveis de governo com os $10 \%$ restantes que deveriam totalizar os $25 \%$ vinculados constitucionalmente (art. 212 da CF/1988).

Ainda na Lei $n^{\circ}$ 9.424/1996, a distribuição de recursos para os Fundos dos governos subnacionais também teria que levar em conta uma diferença de gasto por aluno, tendo em vista os níveis de ensino e tipos de estabelecimento, como a $1^{\mathrm{a}}$ a $4^{\mathrm{a}}$ série, $5^{\mathrm{a}}$ a $8^{\mathrm{a}}$ série, estabelecimentos de ensino especial e escolas rurais (art. $2^{\circ}, \S 2^{\circ}$, incisos I a IV).

As diferenciações passaram a ocorrer a partir do ano 2000, segundo os níveis e tipos de estabelecimento de ensino, com exceção das escolas rurais, incluídas nos dois últimos anos de vigência do Fundo. Esses critérios foram considerados para determinar os coeficientes de distribuição utilizados para compor as receitas dos Fundos de cada estado e seus municípios (art. $2^{\circ}, \S 1^{\circ}$, do Decreto $n^{\circ} 2.264 / 1997$ ).

Coube ao MEC (art. $2^{\circ}$, $\S 4^{\circ}$, da Lei $\mathrm{n}^{\circ}$ 9.424/1996), via Instituto Nacional de Estudos e Pesquisas Educacionais Anísio Teixeira (INEP), a realização do censo educacional, publicado anualmente no Diário Oficial da União (DOU), cujos resultados referentes ao número de estudantes matriculados nas escolas das respectivas redes de ensino deveriam se constituir base para o cálculo do valor aluno/ano. Gomes (2009, p. 667), para fins didáticos, dividiu a operacionalização do Fundef em quatro passos:

1) retenção de valores no fundo estadual; 2) cálculo do valor médio aluno/ano em cada estado; 3) redistribuição de acordo com o número de matrículas feitas no ensino fundamental; e 4) complementação da União nos estados e municípios abaixo da média nacional (definida anualmente pelo governo federal).

Os governos municipais e o governo estadual de cada estado contribuíram, proporcionalmente, para a composição do Fundo. Os recursos retornaram aos governos dos estados (Distrito Federal) e municípios, conforme o número de matrículas (do ano anterior) no ensino fundamental público de sua competência, multiplicado pelo valor do aluno, a cada ano, gerado nos estados e no Distrito Federal, segundo seus esforços fiscais.

Nos estados que não alcançaram o valor mínimo por aluno decretado anualmente pelo presidente da República, depois de estabelecido pelos Ministérios da Educação, da Fazenda e do Planejamento, Orçamento e Gestão (art. $7^{\circ}$ do Decreto $n^{\circ}$ 2.264/1997), houve a complementação da União, até que pudessem atingi-lo.

Para os governos subnacionais que contribuíram com mais do que receberam, registraram perdas de recursos, já para os que receberam mais do que contribuíram, houve acréscimo de receita para a MDE fundamental público. Assim, Martins (2009, p. 131), referindo-se também ao Fundeb, coloca que "os fundos corrigem ou distorcem o equilíbrio 
federativo, nos aspectos da correta dosagem entre encargos e rendas e em relação à autonomia".

A movimentação de perdas e ganhos dentro de um mesmo estado, segundo Davies (2001, p. 42) correspondeu "fundamentalmente a uma redistribuição da miséria existente", pois além das falhas no cumprimento do papel redistributivo da União e da não injeção de novos recursos para o financiamento do ensino fundamental público, não houve uma Reforma Tributária que pudesse reduzir as disparidades fiscais entre os entes federados.

No ano de 1998, 2.703 municípios no país (à época 49\%) ganharam recursos com o Fundef (os quais responderam por $81 \%$ das matrículas de toda a rede municipal), enquanto $2.803(51 \%)$ sofreram perdas (respondendo por 19,0\% das matrículas na rede municipal) (VAZQUEZ, 2003).

Conforme o autor, para o primeiro ano de vigência do Fundo em todo o país, no âmbito dos municípios, apesar da quase paridade entre ganhadores e perdedores, o número de alunos beneficiados com recursos adicionais do Fundo, devido aos efeitos de suas redistribuições intraestaduais, foi significativamente maior do que os que foram prejudicados com a redução das receitas locais.

Em 2004, os índices aumentaram ainda mais, quando aproximadamente 91,6\% dos alunos matriculados no ensino fundamental público foram beneficiados com o Fundef, enquanto o número de municípios cresceu para 3.780 (68\% do total) (BORGES, 2007).

Devido à escassez de recursos para a educação no âmbito dos municípios, alguns deles desenvolveram mecanismos para descumprir a lei, incluindo, por exemplo, no cômputo dos recursos do Fundef, matrículas que não integravam o ensino fundamental, o que, por sua vez, "não só tende a gerar distorção na alocação de recursos, como também reduz a qualidade das estatísticas disponíveis" (SANTOS, 2006, p. 115). Davies (2001, p. 26) relata algumas das irregularidades ocorridas durante a vigência do Fundef, como:

[...] transporte escolar fantasma, desvio de finalidade de veículos a serviço da educação, "clonagem" de alunos, pagamento fictício a professores, que assinam o recibo com valor superior ao que efetivamente receberam, nãodisponibilização pelo Banco do Brasil de dados referentes à conta-Fundef, inclusão de recursos do Fundef, que deveria estar em conta única específica, em contas gerais do ente federativo, retirada de recursos da conta Fundef (única específica) para outras contas, aplicação dos recursos em despesas que não podem ser consideradas como de manutenção e desenvolvimento do ensino (as principais ocorrências referem-se a despesas com merenda escolar), inexistência ou não-aplicação de plano de cargos e carreira, inexistência ou falta de condições de trabalho dos conselhos de acompanhamento e controle social, falta de informações aos conselhos.

A busca pela elevação do número de alunos no ensino fundamental público - já que novas matrículas significavam mais recursos -, nas redes estaduais e municipais, em todo o país, para Araújo (2007), determinaram a ampliação da competição federativa na área educacional.

Contudo, o Fundef teve como um de seus principais objetivos, o de melhorar a cooperação federativa, por meio do regime de colaboração entre os entes federados, no intuito de suprir as necessidades financeiras segundo as responsabilidades que foram assumidas por cada nível de governo para promover a MDE fundamental público, sua universalização e ampliação na qualidade do serviço oferecido, sobretudo pela valorização do magistério. 
Como as disparidades econômicas são muito grandes no território brasileiro, as mesmas foram refletidas nas receitas das contas dos governos estaduais e municipais com os Fundos, embora reduzindo as desigualdades no âmbito de um mesmo estado.

No entanto, a complementação da União (conforme veremos na próxima seção), principal instrumento para amenizar as disparidades interestaduais no financiamento do ensino fundamental público, teve participação percentual na totalidade dos recursos do Fundef reduzida em quase todos os anos de vigência do Fundo.

Para Saviani (1999, p. 37), a EC nº 14/1996 e a Lei n ${ }^{\circ}$ 9.424/1996 tiveram também a responsabilidade de alterar a função do MEC, colocando-o "no centro da formulação, implementação, avaliação e controle das políticas voltadas para esse nível de ensino", sem ter que custear sua manutenção.

Os vetos à Lei do Fundef, em número de três, perduraram durante sua vigência, inclusive no governo de Luiz Inácio Lula da Silva (Lula), quando os movimentos organizados da sociedade civil associados à educação esperavam que fossem retirados.

Para o primeiro, não considerou a inclusão das matrículas da Educação de Jovens e Adultos (EJA) (art. $2^{\circ}, \S 1^{\circ}$, inciso II); no segundo, impediu o estabelecimento de critérios de distribuição dos recursos do salário-educação para os municípios (art. $6^{\circ}, \S 5^{\circ}$ ); por fim, não se proibiu a utilização dessa contribuição social para a complementação da União (art. $15^{\circ}, \S 2^{\circ}$ ).

O Decreto $n^{\circ}$ 2.264/1997 limitou em 20\% o uso do salário-educação na complementação do Fundef realizada pela União (art. $4^{\circ}$ ), via FNDE. Com isso, descumpriu-se em parte a função principal dessa contribuição social, que tem por finalidade financiar programas, projetos e ações voltados para a educação básica pública.

Para Callegari (2002), o Fundef correspondeu a um Fundo de redistribuição, que contribuiu para o avanço da relação entre o financiamento do ensino fundamental público e as responsabilidades educacionais dos níveis de governo. Conforme o autor, o mesmo constituiu-se essencialmente em um Fundo de gestão, no que diz respeito às decisões e aos procedimentos para viabilizá-lo, suas formas de arrecadação e administração dos recursos. Assim, pode ser considerado como:

[...] uma conta titulada na contabilidade governamental, cujo título a identifica para fins administrativos dirigidos; com identidade administrativa, mas destituído de personalidade jurídica. $\mathrm{Na}$ administração pública, fundo também é uma "caixa especial" que mantém e movimenta recursos financeiros em separado do "caixa geral"; uma exceção ao princípio de "unidade de caixa", ou "caixa único", que orienta a gestão dos dinheiros públicos (IDEM, IBIDEM, p. 14).

As quatro principais funções do Fundef, de acordo com Arelaro (1999), estiveram relacionadas com: 1) justiça social; 2) equidade na política educacional; 3) aumento da descentralização; e 4) melhorias na qualidade educacional e valorização do magistério. No próximo tópico, serão analisadas algumas das características fiscais para o Fundef, entre os anos de 1998 a 2006. 


\section{A dinâmica fiscal no Fundef}

Os impostos constituem a principal fonte de financiamento da educação, seguidos pelo salário-educação ${ }^{5}$ que, juntos, englobam a quase totalidade dos recursos, já que as fontes não-tributárias têm pequeno peso sobre o montante global.

Pretende-se, nesta parte, discutir os dados dos gastos educacionais do Fundef com a dinâmica das receitas relacionadas à sua base de arrecadação, além das contribuições de estados e municípios durante o período de sua vigência.

O Gráfico 1 mostra a contribuição e receita dos estados e municípios ao Fundef (de 1998 a 2006), a preços referentes ao último ano, no que diz respeito aos $15 \%$ dos impostos e transferências, conforme suas fontes de financiamento.

Gráfico 1: Contribuição e Receita dos Estados e Municípios ao FUNDEF (de 1998 a 2006), a preços referentes ao último ano ( $\mathrm{R} \$$ bilhões)

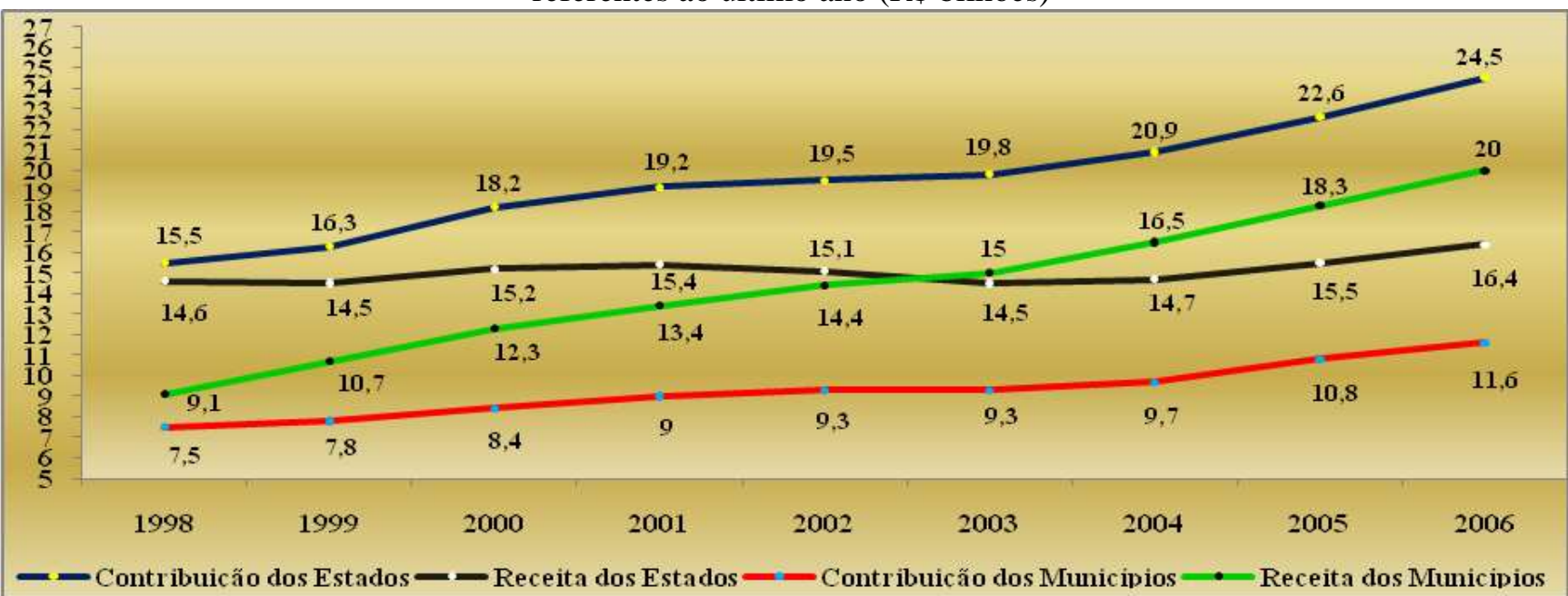

Fonte: Borges (2007).

Elaboração do autor.

Nesse sentido, destacou-se o crescimento da receita dos municípios, que alcançaram, em média, aproximadamente $119,8 \%$, quando passaram de $\mathrm{R} \$ 9,1$ bilhões para $\mathrm{R} \$ 20,0$ bilhões. As receitas dos estados aumentaram 12,3\%, saindo de R $\$ 14,6$ bilhões, em 1998, para R \$ 16,4 bilhões, em 2006.

O baixo desempenho estadual ocorreu em virtude das transferências de recursos aos governos municipais para financiar a elevação do número de matrículas no ensino fundamental público sob sua responsabilidade. Contudo, esse rápido processo não impediu as séries de problemas administrativos na gestão dos recursos, tanto pelos estados quantos pelos municípios, a exemplo dos que foram descritos por Davies (2001), alguns deles já apontados neste trabalho.

Conforme a Tabela 1, a principal fonte de financiamento do Fundef, de 1998 a 2006, majoritariamente consistiu no ICMS, o qual apresentou um crescimento médio, a preços correntes, de aproximadamente $183,1 \%$, cuja arrecadação aumentou de $\mathrm{R} \$ 8.758,86$ milhões para $\mathrm{R} \$ 24.795,40$ milhões. 
Tabela 1: Receitas anuais do Fundef, a preços correntes (nominais), segundo suas fontes de recursos

(R\$ milhões), de 1998 a 2006

\begin{tabular}{c|r|r|r|r|r|r|r||r|r}
\hline \hline & $\mathbf{1 9 9 8}$ & $\mathbf{1 9 9 9}$ & $\mathbf{2 0 0 0}$ & $\mathbf{2 0 0 1}$ & $\mathbf{2 0 0 2}$ & $\mathbf{2 0 0 3}$ & $\mathbf{2 0 0 4}$ & $\mathbf{2 0 0 5}$ & $\mathbf{2 0 0 6}$ \\
\hline \hline FPE & $1.638,05$ & $1.814,20$ & $2.149,85$ & $2.529,97$ & $3.142,91$ & $3.287,60$ & $3.590,39$ & $4.533,59$ & $4.973,10$ \\
FPM & $1.838,32$ & $2.045,91$ & $2.238,73$ & $2.626,91$ & $3.237,98$ & $3.351,74$ & $3.728,60$ & $4.634,51$ & $5.193,29$ \\
IPI-exp. & 237,99 & 239,88 & 264,62 & 284,70 & 281,72 & 270,53 & 323,03 & 366,62 & 412,90 \\
Comp. União & 486,70 & 579,90 & 485,50 & 391,60 & 320,50 & 361,60 & 559,90 & 395,30 & 313,70 \\
LC 87/1996 & 314,00 & 582,91 & 565,67 & 535,00 & 591,29 & 611,18 & 508,65 & 508,85 & 375,03 \\
ICMS & $8.758,86$ & $9.886,71$ & $11.924,68$ & $13.519,21$ & $15.275,09$ & $17.319,82$ & $19.901,08$ & $22.305,94$ & $24.795,40$ \\
TOTAL & $\mathbf{1 3 . 2 7 5 , 4 4}$ & $\mathbf{1 5 . 1 4 9 , 5 1}$ & $\mathbf{1 7 . 6 4 9 , 0 0}$ & $\mathbf{1 9 . 8 8 8 , 4 1}$ & $\mathbf{2 2 . 8 4 9 , 4 9}$ & $\mathbf{2 5 . 2 0 2 , 4 7}$ & $\mathbf{2 8 . 6 1 1 , 6 5}$ & $\mathbf{3 2 . 7 4 4 , 8 1}$ & $\mathbf{3 6 . 0 6 3 , 4 2}$ \\
\hline \hline
\end{tabular}

Fonte: STN.

Elaboração do autor.

O FPM e o FPE, depois do ICMS, compuseram duas outras importantes fontes de financiamento do Fundef. De 1998 a 2006, o crescimento médio para o primeiro correspondeu a aproximadamente $182,5 \%$, passando de $\mathrm{R} \$ 1.838,32$ milhões para $\mathrm{R} \$$ 5.193,29 milhões; já para o segundo, o aumento chegou a 203,6\%, saindo de $\mathrm{R} \$ 1.638,5$ milhões para $\mathrm{R} \$ 4.973,10$ milhões.

As formas de contribuição dos impostos para o financiamento do Fundef foi bastante diversificada no território brasileiro. No caso do ICMS, a participação nas regiões Sudeste, Sul e Centro-Oeste (mais industrializadas), segundo dados da STN, englobou mais da metade dos recursos nos respectivos Fundos estaduais, enquanto que nas demais regiões (menos industrializadas), na maior parte dos estados, a contribuição ficou abaixo da média nacional, em virtude das fortes desigualdades no desenvolvimento econômico do país.

Em contrapartida, a atuação do FPE ocorreu - para boa parte dos estados das regiões Norte e Nordeste -, de maneira oposta quando comparada à do ICMS, ou seja, regiões economicamente menos desenvolvidas acabaram por ter maior dependência das transferências realizadas pelo governo federal, assim, destacou-se sua importante contribuição para os recursos dos Fundos estaduais nesses locais.

A Tabela 2 evidencia, em termos percentuais, as contribuições das fontes de recursos do Fundef, de 1998 a 2006. A participação do ICMS esteve sempre acima dos $65 \%$ em relação ao total das fontes de recursos para o Fundo, enquanto a do FPM, entre $13 \%$ e 15\%, e a do FPE, entre $12 \%$ e $14 \%$.

Tabela 2: Receitas anuais do Fundef, segundo as fontes de recursos (\%), de 1998 a 2006

\begin{tabular}{c|c|c|c|c||c||c||r||r||r}
\hline \hline & $\mathbf{1 9 9 8}$ & $\mathbf{1 9 9 9}$ & $\mathbf{2 0 0 0}$ & $\mathbf{2 0 0 1}$ & $\mathbf{2 0 0 2}$ & $\mathbf{2 0 0 3}$ & $\mathbf{2 0 0 4}$ & $\mathbf{2 0 0 5}$ & $\mathbf{2 0 0 6}$ \\
\hline \hline IPI-exp. & 1,80 & 1.60 & 1,50 & 1,40 & 1,20 & 1,10 & 1,10 & 1,10 & 1,10 \\
Comp. União & 3,70 & 3,80 & 2,80 & 2,00 & 1,40 & 1,40 & 2,00 & 1,20 & 0,90 \\
LC no 87/1996 & 2,40 & 3,80 & 3,20 & 2,70 & 2,60 & 2,40 & 1,80 & 1,60 & 1,00 \\
FPE & 12,30 & 12,00 & 12,20 & 12,70 & 13,80 & 13,00 & 12,50 & 13,80 & 13,80 \\
FPM & 13,80 & 13,50 & 12,70 & 13,20 & 14,20 & 13,30 & 13,00 & 14,20 & 14,40 \\
ICMS & 66,00 & 65,30 & 67,60 & 68,00 & 66,80 & 68,80 & 69,60 & 68,10 & 68,80 \\
TOTAL & $\mathbf{1 0 0}$ & $\mathbf{1 0 0}$ & $\mathbf{1 0 0}$ & $\mathbf{1 0 0}$ & $\mathbf{1 0 0}$ & $\mathbf{1 0 0}$ & $\mathbf{1 0 0}$ & $\mathbf{1 0 0}$ & $\mathbf{1 0 0}$ \\
\hline \hline
\end{tabular}

Fonte: STN.

Elaboração do autor. 
As fontes que contribuíram com a menor quantidade de recursos para o Fundef, de 1998 a 2006, como no caso da LC nº 87/1996, do IPI-exp. e da complementação da União tiveram redução média na participação do Fundo, respectivamente de 1,4 pontos percentuais (p.p.), 0,7 p.p. e 2.8 p.p.

Ainda que pequena diante dos recursos despendidos pelos governos subnacionais para a composição do Fundef, segundo Castro e Duarte (2008), a necessidade de complementação dos recursos do Fundo, por parte da União, demonstrou as fortes diferenças socioeconômicas regionais no território brasileiro.

Tais características foram também atribuídas ao financiamento do ensino fundamental público, constituindo-se barreiras importantes para o avanço da universalização e da qualidade desse nível de ensino.

Com o valor mínimo aluno/ano à mercê da decisão presidencial e não dos preceitos e determinações legais, a complementação da União (principal mecanismo para reduzir as desigualdades interestaduais) foi administrada, durante toda a vigência do Fundef, pelo governo federal. A Tabela 3 evidencia os descompassos entre o gasto aluno/ano real versus o legal.

Tabela 3: Gasto real e gasto legal, por aluno/ano, a preços correntes (nominais), durante a vigência do Fundef, de 1997 a 2006

\begin{tabular}{|c|c|c|c|c|c|c|}
\hline & \multicolumn{2}{|c|}{$\begin{array}{c}\text { Gasto aluno/ano estabelecido } \\
\text { pelo governo federal }(\mathrm{R} \$)\end{array}$} & \multicolumn{2}{|c|}{$\begin{array}{l}\text { Gasto legal }(\mathrm{R} \$) \\
\left(\text { art. }^{\circ}, \$^{\circ}, \text { da Lei } \mathrm{n}^{\circ} 9.424 / 1996\right)\end{array}$} & \multirow[b]{2}{*}{$\begin{array}{c}{[(\mathbf{a}) /(\mathbf{c})]^{* 100}} \\
(\%)\end{array}$} & \multirow[b]{2}{*}{$\begin{array}{c}{[(\mathbf{b}) /(\mathbf{d})]^{*} \mathbf{1 0 0}} \\
(\%)\end{array}$} \\
\hline & $\begin{array}{c}1^{\mathrm{a}} \mathrm{a} 4^{\mathrm{a}} \text { séries } \\
\text { (a) }\end{array}$ & $\begin{array}{c}5^{\mathrm{a}} \text { a } 8^{\mathrm{a}} \text { séries } \\
\text { e Educação } \\
\text { Especial } \\
\text { (b) }\end{array}$ & $\begin{array}{c}1^{\mathrm{a}} \mathrm{a} 4^{\mathrm{a}} \text { séries } \\
\text { (c) }\end{array}$ & $\begin{array}{c}5^{\mathrm{a}} \text { a } 8^{\mathrm{a}} \text { séries } \\
\text { e Educação } \\
\text { Especial. } \\
\text { (d) }\end{array}$ & & \\
\hline 1997 & 300,00 & 300,00 & 405,28 & 405,28 & $\overline{74,0}$ & 74,0 \\
\hline 1998 & 315,00 & 315,00 & 423,55 & 423,55 & 74,3 & 74,3 \\
\hline 1999 & 315,00 & 315,00 & 458,26 & 458,26 & 68,7 & 68,7 \\
\hline 2000 & 333,00 & 349,65 & 517,58 & 543,46 & 64,3 & 64,3 \\
\hline 2001 & 363,00 & 381,15 & 592,76 & 622,40 & 61,2 & 61,2 \\
\hline 2002 & 418,00 & 438,90 & 693,90 & 728,60 & 60,2 & 60,2 \\
\hline 2003 & 462,00 & 485,10 & 769,95 & 808,45 & 60,0 & 60,0 \\
\hline 2004 & 564,63 & 592,85 & 893,35 & 938,02 & 63,2 & 63,2 \\
\hline 2005 - urbano & 620,56 & 651,59 & $1.037,62$ & $1.089,50$ & 59,8 & 59,8 \\
\hline rural & 632,97 & $664,00^{1}$ & $1.058,37$ & $1.110,25$ & 59,8 & 59,8 \\
\hline 2006 - urbano & 682,60 & 716,73 & $1.162,32$ & $1.220,44$ & 58,7 & 58,7 \\
\hline rural & 696,25 & $730,38^{1}$ & $1.185,57$ & $1.243,68$ & 58,7 & 58,7 \\
\hline
\end{tabular}

(1) Valores para a educação especial em 2005 e 2006.

Fonte: Araújo (2007); Monlevade e Ferreira (1997); Oliveira (2008).

Elaboração do autor.

Desde 1997, antes da implantação do Fundef em todo o país, o valor determinado já descumpria a Lei $\mathrm{n}^{\circ} 9.424 / 1996$ (art. $6^{\circ}, \S 1^{\circ}$ ), no entanto, foi justificado que, apenas para aquele ano, o valor real corresponderia a $\mathrm{R} \$ 300,00$, aproximadamente $74,0 \%$ do valor legal previsto.

Daí em diante, a desvalorização do gasto real continuou a se acentuar em quase todos os anos, até 2006, atingindo valores menores a $60 \%$ em relação ao gasto legal (previsto). Uma das justificativas para a diminuição dos recursos federais para financiar o ensino fundamental público esteve associada à produção de superávits primários, no intuito de garantir o cumprimento dos compromissos externos e internos, a exemplo do pagamento dos juros da dívida pública, que favoreceram principalmente as elites locais e internacionais. 
A diferenciação entre o $1^{\circ}$ e o $2^{\circ}$ segmento do ensino fundamental, bem como para a educação especial, passou a ocorrer em 2000, por meio de decretos presidenciais. Os fatores de ponderação foram estabelecidos tendo como base as séries iniciais do ensino fundamental $(1,00)$, com o crescimento de $5 \%$ para as séries finais e a educação especial $(1,05)$.

Menezes (2005) destacou as perdas de alguns estados, em 1998 e 1999, pela não diferenciação entre os valores aluno/ano entre as séries iniciais e finais do ensino fundamental público, com o rápido processo de transferência de matrículas de $1^{\mathrm{a}}$ a $4^{\mathrm{a}}$ séries desses governos estaduais, desencadeado pelo Fundef, para muitos de seus municípios, já que os alunos de $5^{\mathrm{a}}$ a $8^{\mathrm{a}}$ séries, em boa parte sob a responsabilidade estadual, teriam um valor mais elevado.

Já no final da vigência do Fundef, em 2005, os fatores foram aplicados para as escolas rurais, assim estabelecidos: $1^{\mathrm{a}}$ a $4^{\mathrm{a}}$ séries das escolas urbanas $(1,00) ; 1^{\mathrm{a}}$ a $4^{\mathrm{a}}$ séries das escolas rurais $(1,02) ; 5^{\mathrm{a}}$ a $8^{\mathrm{a}}$ séries das escolas urbanas $(1,05) ; 5^{\mathrm{a}}$ a $8^{\mathrm{a}}$ séries das escolas rurais e educação especial das escolas rurais e urbanas $(1,07)$.

Para Vazquez (2003), o principal fator para a ilegalidade na determinação do valor aluno/ano, estabelecido durante o Fundef, relacionou-se com a crise econômica no final do século XX no Brasil (antecedida pela crise asiática e da Rússia), tendo sido "lamentável" (PINTO, 1999, p. 87) o governo federal ter enviado e feito aprovar uma emenda constitucional e uma lei que não foi cumprida em pontos importantes.

O congelamento do valor aluno/ano em 1999 (única ocasião em que não houve aumento), bem como sua desvalorização durante todo o período do Fundef, contribuiu para a redução do papel do governo federal relacionado à injeção de novos recursos para a MDE fundamental público.

O primeiro governo Lula, ao contrário do que se pensava antes da entrada do PT na presidência da República, reforçou a tendência de desvalorização do valor aluno/ano. Ao citar a Confederação Nacional dos Trabalhadores em Educação (CNTE), Martins (2009) demonstrou a insatisfação dessa entidade com a redução dos recursos referentes à complementação da União, já que o discurso anterior à posse do novo presidente chamava a atenção para a necessidade de retirar a ilegalidade imposta pelo governo federal anterior.

Na comparação entre os estados de São Paulo e Maranhão, em relação ao valor aluno/ano para 1998 e 2005, Borges (2007) ressaltou: 1) a importância do Fundo para os locais que se encontravam em condições precárias, ou próximas a elas, quanto ao oferecimento do ensino fundamental público; 2) a diminuição das diferenças do valor aluno/ano entre a rede municipal e estadual de ensino em um mesmo estado; bem como 3) o aumento de recursos para os estados que receberam a complementação da União (diminuindo diferenças interestaduais, ainda que em escala reduzida).

A determinação de um valor aluno/ano diferente daquele disposto na lei do Fundef elevou as desigualdades entre os dois estados, pois em 1998, São Paulo gastou R\$ 657,42, por aluno, enquanto o Maranhão, $\mathrm{R} \$ 315,00$ (diferença de aproximadamente 108,7\%). No ano de 2005, esses valores corresponderam respectivamente a $\mathrm{R} \$ 1.665,03$ e $\mathrm{R} \$ 642,28$ (diferença de 159,2\%). Assim, o autor conclui:

Para que, em 2005, o Maranhão estivesse com a mesma desigualdade verificada em 1998 (109\%) em relação a São Paulo, o valor mínimo nacional nesse exercício deveria ter alcançado a média de $\mathrm{R} \$ 797,00$. O que se verificou, entretanto, foi um valor mínimo médio $19,4 \%$ menor. Confirma-se, nesse aspecto, a perspectiva apontada por Melchior (1997) e 
Davies (1999) de que o FUNDEF não contornaria, apenas atenuaria, a desigualdade (IDEM, IBIDEM, p. 67).

De acordo com a Tabela 4, em termos percentuais, quando comparada com o total anual de recursos do Fundef, a complementação da União, com exceção de 1999 e 2004, praticamente teve redução contínua de 1998 a 2006, em que os 3,7\% referentes ao total do Fundo no primeiro ano, foram reduzidos para $0,9 \%$ no último.

Tabela 4: Complementação da União e sua previsão legal, a preços correntes (nominais), durante a vigência do Fundef em todo o país, de 1998 a 2006

\begin{tabular}{|c|c|c|c|c|c|c|}
\hline & \multicolumn{2}{|c|}{$\begin{array}{c}\text { Complementação da } \\
\text { União }\end{array}$} & \multicolumn{2}{|c|}{$\begin{array}{c}\text { Complementação } \\
\text { prevista em lei } \\
\text { art. }^{\circ} \text {, da Lei no 9.424/1996) }\end{array}$} & \multirow{2}{*}{\begin{tabular}{|c}
$\begin{array}{c}\text { Diferença entre a } \\
\text { complementação } \\
\text { da União e a } \\
\text { prevista }\end{array}$ \\
R\$ milhões \\
(c)
\end{tabular}} & \multirow{2}{*}{$\begin{array}{c}\text { Recursos do Fundef } \\
\text { sem a } \\
\text { complementação da } \\
\text { União } \\
\mathrm{R} \$ \text { milhões } \\
\text { (d) }\end{array}$} \\
\hline & $\begin{array}{c}\mathrm{R} \$ \text { milhões } \\
\text { (a) }\end{array}$ & $\begin{array}{c}(\mathrm{a}) /(\mathrm{d})] * 100 \\
(\%)\end{array}$ & $\begin{array}{l}\text { R\$ milhões } \\
\text { (b) }\end{array}$ & $\begin{array}{c}{[(\mathrm{b}) /(\mathrm{d})]} \\
(\%) \\
(\%)\end{array}$ & & \\
\hline 1998 & 486,7 & 3,7 & $2.060,6$ & 16,1 & $1.573,9$ & $12.788,7$ \\
\hline 1999 & 579,9 & 3,8 & $2.686,4$ & 18,4 & $2.106,4$ & $14.569,6$ \\
\hline 2000 & 485,5 & 2,8 & $3.128,0$ & 18,2 & $2.642,5$ & $17.163,5$ \\
\hline 2001 & 391,6 & 2,0 & $3.503,9$ & 17,6 & $3.112,3$ & $19.946,8$ \\
\hline 2002 & 320,5 & 1,4 & $3.899,2$ & 17,3 & $3.578,7$ & $22.529,0$ \\
\hline 2003 & 361,6 & 1,4 & $4.346,6$ & 17,5 & $3.984,5$ & $24.840,9$ \\
\hline 2004 & 559,9 & 2,0 & $4.795,0$ & 17,1 & $4.235,1$ & $28.051,8$ \\
\hline 2005 & 395,3 & 1,2 & $5.098,5$ & 15,8 & $4.703,2$ & $32.349,5$ \\
\hline 2006 & 313,7 & 0,9 & $5.756,0$ & 16,1 & $5.442,3$ & $35.749,7$ \\
\hline TOTAL & $3.895,3$ & - & $35.274,2$ & - & $31.378,9$ & $207.989,5$ \\
\hline
\end{tabular}

Fonte: Borges (2007); STN.

Elaboração do autor.

De 1998 a 2006, durante a vigência do Fundef, a União deixou de aplicar no ensino fundamental público, mais de $\mathrm{R} \$ 30$ bilhões (a preços correntes), quase $60 \%$ desse montante acumulado no governo Lula. Novamente, ao comparar o real versus o legal, para a complementação da União, evidencia-se que seu valor teria correspondido sempre a mais de $15 \%$ do montante dos recursos estaduais e municipais destinados ao Fundo, em que deveria ter alcançado 18,4\%, em 1999.

A Tabela 5, que tem por objetivo evidenciar os estados contemplados com a complementação da União durante a vigência do Fundef, em todo o país, de 1998 a 2006, revela que o não cumprimento do ordenamento legal associado ao cálculo do valor aluno/ano, por parte da União, contribuiu para que o número de estados beneficiados com a referida complementação fosse progressivamente diminuindo, até que em 2006, apenas dois, Maranhão e Pará, receberam a complementação. 
Tabela 5: Complementação da União ( $\mathrm{R} \$$ milhões), a preços correntes (nominais), aos estados que não alcançaram o mínimo definido para o valor aluno/ano, de 1998 a 2006

\begin{tabular}{|c|c|c|c|c|c|c|c|c|c|}
\hline Estados & 1998 & 1999 & 2000 & 2001 & 2002 & 2003 & 2004 & 2005 & 2006 \\
\hline Alagoas & - & 3,2 & - & - & - & - & $\overline{24,7}$ & $\overline{10,4}$ & - \\
\hline Bahia & 143,9 & 215,1 & 191,2 & 163,5 & 112,0 & 97,2 & 99,6 & - & - \\
\hline Ceará & 46,4 & 33,5 & 2,9 & - & - & - & 4,5 & - & - \\
\hline Maranhão & 153,5 & 174,5 & 168,9 & 146,8 & 145,1 & 188,9 & 239,5 & 236,6 & 202,4 \\
\hline Pará & 112,5 & 116,5 & 94,2 & 61,6 & 46,8 & 50,9 & 155,5 & 127,9 & 111,3 \\
\hline Paraíba & - & 4,7 & - & - & - & - & - & - & - \\
\hline Pernambuco & 6,3 & 8,1 & - & - & - & - & - & - & - \\
\hline Piauí & 24,1 & 24,3 & 28,3 & 19,7 & 16,6 & 24,6 & 36,1 & 20,4 & - \\
\hline TOTAL & 486,7 & 579,9 & 485,5 & 391,6 & 320,5 & 361,6 & 559,9 & 395,3 & 313,7 \\
\hline
\end{tabular}

Fonte: Borges (2007).

O valor gasto em 2006 representou aproximadamente 64,5\% (a preços correntes) da complementação de 1998. As significativas diferenças econômicas entre as regiões brasileiras foram detectadas por meio da concentração de estados do Nordeste no recebimento da complementação da União.

Nesse sentido, os governos FHC e Lula mantiveram a mesma lógica de diminuição da complementação, em certa medida, comprometendo a finalidade do Fundef de contribuir para com a redução das desigualdades educacionais entre as regiões brasileiras, presentes no ensino fundamental público.

As mudanças produzidas com o Fundef no financiamento do ensino fundamental público no país não comportariam a ruptura do que havia sido construído, principalmente para os governos municipais, que elevaram, de forma significativa, suas receitas, o número de alunos e "ajustaram os níveis de remuneração do seu contingente de profissionais do magistério" (BORGES, 2007, p. 92).

A discussão da criação de um Fundo para financiar toda a educação básica pública ocorreu antes mesmo da aprovação do Fundef, com a PEC no 233/1995. Muitas propostas para ampliar e redistribuir os recursos estiveram nas negociações políticas entre os governos e entidades da sociedade civil, inclusive no Congresso Nacional, onde foram apresentadas diversas proposições, até que a Lei $\mathrm{n}^{\circ}$ 11.494/2007 viesse a regulamentar o Fundeb, que reformou o Fundef.

\section{O processo de regulamentação do Fundeb}

No ano de 1997, antes mesmo que o Fundef tivesse entrado em vigor ao longo de todo o território brasileiro, a PEC $n^{\circ}$ 536/1997 apresentada pelo deputado federal Valdemar Costa Neto, filiado ao Partido Liberal (PL) de São Paulo, propôs a criação do Fundeb (art. $2^{\circ}$ ), por meio da modificação da CF/1988 (art. 60 do ADCT).

A PEC n ${ }^{\circ} 536 / 1997$ foi apensada a outras Propostas que passaram pelo Legislativo federal até a aprovação do Fundeb. A última delas correspondeu à PEC no 415/2005, apresentada pelo governo federal - quando Lula caminhava para o terceiro ano de seu primeiro mandato -, ao estabelecer nova dinâmica para o processo legislativo do Fundo (OLIVEIRA, 2009), tendo sido aprovada no final de 2006.

Mais uma vez, evidenciou-se a preponderância do Executivo sobre o Legislativo na aprovação de matérias de interesse federativo, nesse caso, por meio de um Fundo contábil único que desconsiderou algumas das propostas de implantação de Fundos separados ou mesmo a prorrogação do Fundef. Araújo (2007, p. 10) afirma que: 


\begin{abstract}
Não podemos afirmar que houve subordinação do governo federal aos interesses estaduais, mas sim concessões parciais a estes interesses, como ficou claro na não inclusão das matrículas da creche na proposta de emenda constitucional enviada ao Congresso e no apoio à gradatividade na implantação do novo fundo.
\end{abstract}

Na ementa da PEC no 415/2005, propôs-se dar nova redação à CF/1988 (art. 212, § $5^{\circ}$; art. 60 do ADCT), com isso, possibilitando a instituição do Fundeb. Segundo Monlevade (2007) e Pinto e Adrião (2006), os principais desafios da Proposta corresponderam: 1) a não incorporação das matrículas das creches; 2) pouca importância dada ao Piso Salarial Profissional Nacional; 3) complementação da União não associada ao percentual do valor total do Fundo; 4) fim do valor aluno/ano; e 5) desconsideração à garantia do padrão mínimo de qualidade no ensino.

Esses fatores estiveram associados, principalmente com a relutância da área econômica do governo, na época chefiada pelo ministro da Fazenda, Antônio Palocci Filho, em expandir um Fundo contábil único para financiar toda a educação básica pública, como defendia o ministro da Educação, Tarso Genro, o que provocou importante mobilização de movimentos sociais associados à educação.

Como exemplo, entre outros, citam-se a CNTE, o "Fundeb pra Valer" - coordenado pela Campanha Nacional pelo Direito à Educação (CNDE) -, a Organização Mundial para Educação Pré-Escolar (OMEP) e o Movimento Interfóruns de Educação Infantil do Brasil (MIEIB).

Novamente, os ajustes fiscais, no caso da produção de superávits primários, dos pagamentos da dívida pública, da responsabilidade fiscal e do controle inflacionário foram confrontados com a perspectiva de inclusão social e a possibilidade de se ampliar a democratização das instituições públicas, fortalecendo os vínculos de cidadania, particularmente na área do financiamento da educação básica pública.

Depois de dezoito meses tramitando no Congresso Nacional, pelas duas casas legislativas, a PEC $n^{\circ} 415 / 2005$ passou por modificações que reestruturaram o texto original, sobretudo as que foram incorporadas pelo Senado federal.

Assim, destacam-se a redução do período para integralizar a complementação da União, inclusão das matrículas das creches e o financiamento das matrículas da educação básica segundo as responsabilidades legais associadas aos estados e municípios para com os níveis e as modalidades de ensino, que receberam a determinação da aplicação de percentuais máximos de recursos, no intuito de evitar a falta de equilíbrio na migração de verbas entre eles (SOUSA, 2006).

Cabe lembrar que a PEC $n^{\circ} 415 / 2005$ tramitou em meio a um dos maiores escândalos (do mensalão) de corrupção tornado público no período democrático brasileiro, que envolveu principalmente o partido do governo e sua base aliada, impondo novos rumos ao funcionamento do Congresso Nacional. O processo legislativo da Proposta foi encerrado com a aprovação, em 19 de dezembro de 2006, da EC $n^{\circ} 53$, regulamentada, nove dias depois, pela MP n 339.

A discussão sobre o regime de colaboração ficou restrita ao papel a ser desempenhado pela União no financiamento da educação básica, já que não foram propostas alterações para as responsabilidades dos entes federados relacionadas com os níveis e as modalidades de ensino, segundo o art. 211 da CF/1988. Vale destacar, ainda, que a EC $\mathrm{n}^{\circ}$ $53 / 2006$ determinou a fixação das normas para a cooperação entre os entes federados, a qual deve ser apresentada por meio de leis complementares (art. $1^{\circ}$ ). 
A operacionalização inicial do Fundeb, determinada pela MP n ${ }^{\circ} 339 / 2006$, até sua conversão na Lei $\mathrm{n}^{\circ} 11.494$, em 20 de junho de 2007, além da crise política, mostrou também os tradicionais conflitos e impasses que envolvem os processos associados aos atos legislativos.

Ora, desde 1997, a Proposta para a criação de um Fundo contábil destinado a financiar toda a educação básica pública havia sido apresentada ao Congresso Nacional, no entanto, mesmo definido o prazo para o término da Lei do Fundef (no final de 2006), foram necessários mais seis meses para que fosse aprovada a Lei do Fundeb.

A EC n ${ }^{\circ}$ 53/2006 deu nova redação aos arts. $7^{\circ}, 23,30,206,208,211$ e 212 da $\mathrm{CF} / 1988$, bem como ao art. 60, do ADCT. Com exceção dos três primeiros, os demais artigos estabeleceram as condições para que fosse criado o Fundeb.

Apesar da pequena inserção de novos recursos, viabilizada com a complementação da União aos Fundos, quando viesse a ocorrer, agora para o financiamento da educação básica, houve uma reestruturação do percentual referente à cota de parte dos impostos e transferências já destinados à MDE, a serem gastos de acordo com as determinações contidas nos arts. 70 e 71 da LDB/1996.

Ainda assim, diversos pontos relacionados à organização e operacionalização dos Fundos foram delegados para lei posterior, primeiro estabelecidos pela MP no 339/2006, e depois pela Lei ${ }^{\circ} 11.494 / 2007$. Conforme a EC $n^{\circ} 53 / 2006$, a lei viria a dispor sobre

[...] a organização dos Fundos, a distribuição proporcional de seus recursos, as diferenças e as ponderações quanto ao valor anual por aluno entre etapas e modalidades da educação básica e tipos de estabelecimento de ensino; [...] a forma de cálculo do valor anual mínimo por aluno; [...] os percentuais máximos de apropriação dos recursos dos Fundos pelas diversas etapas e modalidades da educação básica, observados os arts. 208 e 214 da Constituição Federal, bem como as metas do Plano Nacional de Educação; [...] a fiscalização e o controle dos Fundos; [...] prazo para fixar, em lei específica, piso salarial profissional nacional para os profissionais do magistério público da educação básica. (art. $2^{\circ}$ ).

Segundo o art. $2^{\circ}$ da EC no 53/2006, a duração do Fundeb foi estabelecida em 14 anos (até 31 de dezembro de 2020), cuja composição englobou os impostos e transferências que já faziam parte do Fundef, os quais tiveram elevado o percentual de $15 \%$ para $20 \%$, a ser alcançado em três anos (16,66\%, 18,33\% e 20\%), de 2007 a 2009.

Além disso, também inseriu outros três novos, no caso, o Imposto sobre a Propriedade Territorial Rural (ITR - Cota Municipal), Imposto sobre a Propriedade de Veículos Automotores (IPVA) e Imposto de Transmissão Causa Mortis e Doação (ITCMD), que passaram a destinar a cota de seus recursos ao Fundo de forma gradual $(6,66 \%, 13,33 \%$ e 20\%), no triênio determinado (art. 31, § $1^{\circ}$, da MP no 339/2006 e da Lei $n^{\circ} 11.494 / 2007$ ).

Soma-se também a complementação da União que, até 2010, deveria alcançar $10 \%$ dos recursos despendidos pelos governos subnacionais aos Fundos, além dos rendimentos financeiros gerados pelas receitas do Fundeb.

O Quadro 1 evidencia as fontes de recursos do Fundeb, implantadas de forma gradual, de 2007 a 2009, quando comparadas com as do Fundef. 
Quadro 1: Fontes percentuais de recursos do Fundeb, implantadas gradualmente (2007-2009), comparadas com as do Fundef

\begin{tabular}{|c|c|c|c|c|}
\hline \multirow[t]{2}{*}{ Provimento dos Recursos } & \multicolumn{3}{|c|}{ FUNDEB $^{1}(\%)$} & \multirow{2}{*}{$\begin{array}{c}\text { FUNDEF (\%) } \\
(1998)\end{array}$} \\
\hline & $1^{\circ}$ ano (2007) & $2^{\circ}$ ano (2008) & $3^{\circ}$ ano (2009) & \\
\hline ICMS & 16,66 & $\overline{18,33}$ & $\overline{20,00}$ & $\overline{15,00}$ \\
\hline PFE/FPM & 16,66 & 18,33 & 20,00 & 15,00 \\
\hline IPI/Exportação & 16,66 & 18,33 & 20,00 & 15,00 \\
\hline Lei Kandir (LC no 87/1996) & 16,66 & 18,33 & 20,00 & 15,00 \\
\hline ITR - Cota Municipal & 6,66 & 13,33 & 20,00 & \\
\hline IPVA & 6,66 & 13,33 & 20,00 & \\
\hline ITCMD & 6,66 & 13,33 & 20,00 & \\
\hline
\end{tabular}

(1) Além desses impostos e transferências, a MP no 339/2006 e a Lei no 11.494/2007 incluíram os recursos da dívida ativa e juros de mora, o que não foi feito na $\mathrm{EC} \mathrm{n}^{\mathrm{o}}$ 53/2006.

Fonte: Callegari (2008, p. 64).

O Imposto de Renda (IR) dos entes federados e os impostos municipais como o Imposto Predial e Territorial Urbano (IPTU), Imposto sobre Serviços de Qualquer Natureza (ISS) e Imposto de Transmissão de Bens Imóveis Inter-Vivos (ITBI) foram excluídos da cesta do Fundeb, mas continuaram a contribuir com $25 \%$ de suas receitas para a MDE associada à educação básica pública, bem como os $5 \%$ dos impostos vinculados que não entraram nas receitas dos Fundos (art. $1^{\circ}$ da Lei $n^{\circ} 11.494 / 2007$ ).

A inclusão gradativa buscou reduzir o impacto das perdas de recursos que seriam provocadas em alguns níveis de governo, sobretudo nos estados, devido às formas de redistribuição fiscal entre os entes federados, como ocorreu durante a intensa municipalização do ensino fundamental público com o Fundef, que elevou significativamente, no conjunto, as receitas dos municípios com verbas destinadas à educação.

Os recursos passaram a ser distribuídos com a periodicidade das fontes primárias, pelo Tesouro Nacional e pelas instituições fazendárias estaduais, ao Banco do Brasil ou à Caixa Econômica Federal, que os remeteu às contas únicas e específicas dos governos subnacionais. Aos estados e a cada um de seus municípios têm sido atribuídos coeficientes para a distribuição dos recursos, como no Fundef, definidos anualmente.

A Caixa Econômica Federal foi incluída na distribuição dos recursos dos Fundos com a Lei $\mathrm{n}^{\mathrm{o}}$ 11.494/2007 (art. 16). Em janeiro e fevereiro de 2007, manteve-se a sistemática de repartição do Fundef, ou seja, os novos mecanismos determinados pelo Fundeb começaram a operar apenas em $1^{\circ}$ de março, inclusive para a complementação da União (art. 43).

Assim, esses bancos puderam registrar sua movimentação por meio do lançamento de créditos e débitos, em contas próprias, proporcionalmente em função do número de alunos presenciais matriculados nas etapas e modalidades da educação básica, tendo em conta o censo escolar mais atualizado (sob a responsabilidade do INEP), bem como os coeficientes de ponderação a elas atribuídos, no cumprimento das determinações estabelecidas pelo art. $211 \mathrm{da} \mathrm{CF/1988.}$

As matrículas do ensino médio nas redes municipais, além daquelas associadas à educação infantil nas redes estaduais, não receberam receitas dos Fundos. Para financiar as quase 450.000 matrículas, em 2006, que pelas novas determinações estariam fora da repartição do Fundeb, em 2007, restariam os recursos não vinculados aos Fundos e destinados à MDE, ou sua negociação entre os entes federados, conforme as responsabilidades atribuídas a cada nível de governo (ARAÚJO, 2007).

Com o intuito de facilitar possíveis acordos entre os estados e municípios, o art. 18 da Lei n ${ }^{\circ} 11.494 / 2007$ estabeleceu dispositivo que permitiu a criação de convênios "para a 
transferência de alunos, recursos humanos, materiais e encargos financeiros, acompanhados da transferência imediata de recursos financeiros correspondentes ao número de matrículas assumido pelo ente federado".

A distribuição de recursos dos Fundos entre os níveis e modalidades de ensino também foi feita de forma gradual, abarcando todas as matrículas no ensino fundamental e 1/3 no primeiro ano, $2 / 3$ no segundo e a totalidade no terceiro para as da educação infantil, ensino médio e EJA (art. $2^{\circ}$ da EC n ${ }^{\circ} 53 / 2006$; art. 31, $\S 2^{\circ}$, da MP $n^{\circ} 339 / 2006$ e da Lei ${ }^{\circ}$ 11.494/2007).

O Quadro 2 mostra a inclusão progressiva das matrículas, de 2007 a 2009, para os níveis e modalidades de ensino no Fundeb e sua comparação com o Fundef.

Quadro 2: Inclusão progressiva das matrículas (\%) para os níveis e modalidades de ensino no Fundeb e sua comparação com o Fundef

\begin{tabular}{|c|c|c|c|c|}
\hline \multirow{3}{*}{$\begin{array}{c}\text { Níveis e Modalidades } \\
\text { de Ensino }\end{array}$} & \multicolumn{3}{|c|}{ FUNDEB } & FUNDEF \\
\hline & \multicolumn{3}{|c|}{ Inclusão Progressiva (\%) } & Inclusão Progressiva (\%) \\
\hline & $1^{\circ}$ ano (2007) & $2^{\circ}$ ano (2008) & $3^{\circ}$ ano (2009) & 1998 \\
\hline \multicolumn{5}{|l|}{ Educação Infantil } \\
\hline Creche & 33,33 & 66,66 & 100,00 & \\
\hline \multirow{2}{*}{\multicolumn{5}{|c|}{ Ensino Fundamental }} \\
\hline & & & & \\
\hline Séries Iniciais (Urbano) & 100,00 & 100,00 & 100,00 & 100,00 \\
\hline Séries Iniciais (Rural) & 100,00 & 100,00 & 100,00 & 100,00 \\
\hline Séries Finais (Urbano) & 100,00 & 100,00 & 100,00 & 100,00 \\
\hline Séries Finais (Rural) & 100,00 & 100,00 & 100,00 & 100,00 \\
\hline \multicolumn{5}{|l|}{ Ensino Médio } \\
\hline Regular & 33,33 & 66,66 & 100,00 & \\
\hline \multicolumn{5}{|l|}{ Educação Especial } \\
\hline Ensino Fundamental & 100,00 & 100,00 & 100,00 & 100,00 \\
\hline Ensino Médio & 33,33 & 66,66 & 100,00 & \\
\hline EJA & 33,33 & 66,66 & 100,00 & \\
\hline
\end{tabular}

Fonte: Callegari (2008, p. 65).

Com o Fundeb, admitiu-se a inclusão das matrículas das creches (atendimento a crianças de até 3 anos de idade), durante sua vigência, de instituições comunitárias, confessionais ou filantrópicas - inclusive aquelas que atendessem à educação especial -, conveniadas com o Poder Público, descaracterizando seu perfil de um Fundo contábil para financiar a educação básica pública. Davies (2008) classificou a incorporação de inconstitucional e ressaltou o favorecimento aos interesses privatistas no Congresso Nacional.

Para tanto, segundo a Lei $\mathrm{n}^{\circ} 11.494 / 2007$, deveriam ser assegurados os seguintes requisitos: 1) gratuidade e oferta da igualdade de condições para o acesso e permanência na escola; 2) comprovação da finalidade não lucrativa e aplicação dos excedentes financeiros no ensino oferecido; 3) no caso do encerramento de suas atividades, deveriam destinar seu patrimônio para outra instituição com as mesmas finalidades; 4) estabelecer padrões mínimos de qualidade e terem aprovados seus projetos pedagógicos pelo órgão normativo do sistema de ensino; e 5) obter certificação do Conselho Nacional de Assistência Social ou órgão equivalente (art. $8^{\circ}, \S \S 1^{\circ}$ e $2^{\circ}$ ).

Ainda no mesmo artigo, as matrículas da pré-escola, das respectivas instituições, por um período de quatro anos (2007-2010), também foram incorporadas aos Fundos $\left(\S \S 3^{\circ} \mathrm{e}\right.$ $\left.4^{\mathrm{o}}\right)$.

Ao governo federal, segundo o art. 15 da MP no 339/2006 e da Lei $n^{\circ}$ 11.494/2007, determinou-se a tarefa de calcular e publicar, até 31 de dezembro de cada ano, para a 
vigência do próximo exercício: 1) a estimativa de todas as receitas dos Fundos; 2) o valor da complementação da União; 3) o valor aluno/ano nos estados e no Distrito Federal; e 4) o valor aluno/ano mínimo para todo o território brasileiro.

A transparência foi ampliada quando a Medida Provisória e a Lei do Fundeb determinaram, com a mesma redação, que os recursos da União, dos estados e do Distrito Federal destinados aos Fundos fossem detalhadamente registrados, de modo a evidenciar as transferências realizadas (art. 19).

Caso chegue a haver retenção das verbas nos Fundos por prazo superior a quinze dias, devem ser aplicadas em operações financeiras de curto prazo ou de mercado aberto. Os ganhos serão investidos nas mesmas finalidades dos Fundos principais (art. 20). Além disso, $5 \%$ da composição fiscal dos Fundos, inclusive no que se refere à complementação da União, pode ser utilizada no primeiro trimestre do exercício seguinte, com a abertura de crédito adicional financeiro ( $\operatorname{art} .21, \S 2^{\circ}$ ), registrados como "restos a pagar".

A Lei do Fundeb também recebeu três vetos, como no Fundef, dos quais dois trataram de problemas de ordem formal, sem afetar o financiamento do Fundo (parágrafo único do art. 18; parágrafo único do art. 41). O terceiro veto (art. 42) foi direcionado à exclusão de todos os recursos do Fundeb do cálculo da Receita Líquida Real que, de acordo com a organização Ação Educativa, em seu endereço eletrônico, levaria à diminuição das receitas da União, estimadas em R \$ 297 milhões, em 2007, R \$ 626 milhões, em 2008, e R\$ 1.037 milhões, em 2009.

Vejamos adiante, a dinâmica fiscal para o Fundeb, no período compreendido entre os anos de 2007 a 2010.

\section{A dinâmica fiscal no Fundeb (2007-2010)}

O Fundeb inseriu, de forma geral, poucos novos recursos para o financiamento da educação básica. Também manteve a mesma lógica do Fundef, no que se refere aos ganhos entre os governos subnacionais, bem como as perdas, de iguais proporções, principalmente quando houver a falta de complementação da União.

O Gráfico 2 mostra a dinâmica nos gastos dos governos subnacionais, no Fundeb, de 2007 a 2010, bem como sua comparação com o último ano de vigência para o Fundef.

Gráfico 2: Gastos dos governos subnacionais (valores nominais), no Fundeb, de 2007 a 2010, e sua comparação com o último ano de vigência do Fundef

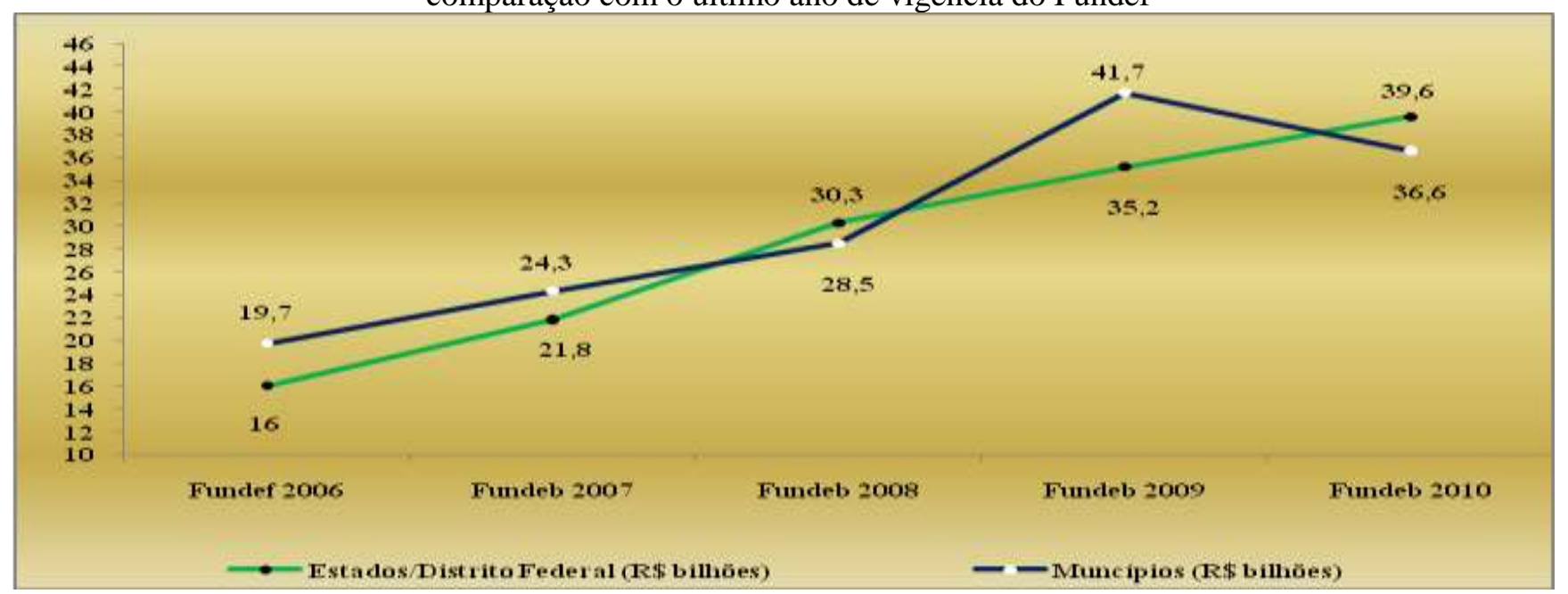

Nota: Não inclui a complementação da União.

Fonte: FNDE; STN.

Elaboração do autor. 
Em 2010, as despesas dos estados e do Distrito Federal foram maiores do que os dos municípios, ao contrário do que ocorreu, por exemplo, nos anos de 2007 e 2009. Além disso, de 2009 para 2010, os gastos municipais sofreram queda de aproximadamente $12,2 \%$, saindo de $\mathrm{R} \$ 41,7$ bilhões, para $\mathrm{R}$ \$ 36,6 bilhões.

Assim, não é possível afirmar, como o fez Martins (2009, p. 232), que continuou a ocorrer o "processo de descentralização de recursos dos estados para os municípios", pelo menos em todo o período observado, em virtude das responsabilidades atribuídas aos governos subnacionais para com os níveis e modalidades de ensino, conforme a LDB/1996.

Quando analisados em termos percentuais, segundo o Gráfico 3, evidencia-se a redução, em média, dos gastos municipais de aproximadamente 6,6 p.p., pois em 2007, sua participação correspondeu a $50,1 \%$ do que foi despendido pelos governos subnacionais, enquanto em 2010, alcançou 43,5\%.

Gráfico 3: Gastos dos governos subnacionais (valores nominais), em termos percentuais, no Fundeb, de 2007 a 2010, e sua comparação com o último ano de vigência do Fundef

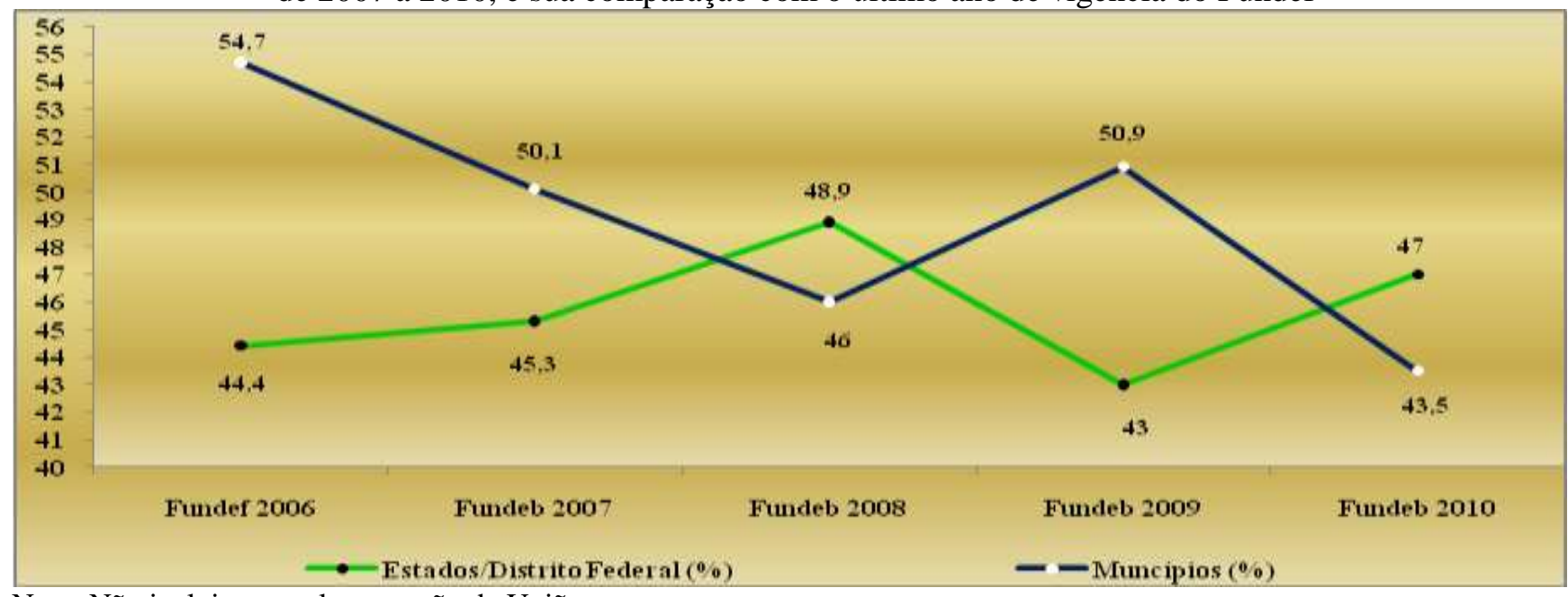

Nota: Não inclui a complementação da União.

Fonte: FNDE; STN.

Elaboração do autor.

No Fundeb, houve a ampliação média dos recursos, em aproximadamente 135,6\%, pois passaram de R \$ 35,7 bilhões, em 2006 (último ano de vigência do Fundef), para R \$ 84,1 bilhões, em 2010. Para o crescimento das matrículas, atingiu 71,7\%, ou seja, saiu de 30,0 milhões, no primeiro ano, para 51,5 milhões, no segundo.

Conforme a Tabela 6, a principal fonte de financiamento do Fundeb, de 2007 a 2010, consistiu no ICMS, que apresentou crescimento médio, a preços correntes, de aproximadamente $74,2 \%$. 
Tabela 6: Receitas anuais do Fundeb, a preços correntes (nominais), segundo suas fontes de recursos (R\$ mil), de 2007 a 2010

\begin{tabular}{c|c|c|c||c}
\hline \hline & $\mathbf{2 0 0 7}$ & $\mathbf{2 0 0 8}$ & $\mathbf{2 0 0 9}$ & $\mathbf{2 0 1 0}$ \\
\hline \hline FPE & 6.398 .612 & 8.607 .378 & 9.051 .603 & 9.756 .024 \\
FPM & 6.696 .219 & 9.007 .723 & 9.472 .505 & 10.209 .791 \\
IPI-exp. & 533.028 & 662.330 & 565.604 & 737.102 \\
Comp. União & 2.012 .399 & 3.174 .300 & 5.070 .150 & 5.353 .310 \\
LC 87/1996 & 324.869 & 357.435 & 390.000 & 390.000 \\
ITR & 11.213 & 25.789 & 57.785 & 90.631 \\
ICMS & 30.056 .750 & 39.460 .755 & 43.999 .140 & 52.348 .254 \\
IPVA & 830.283 & 2.222 .602 & 3.932 .866 & 4.198 .357 \\
ITCMD & 60.176 & 192.709 & 393.062 & 532.384 \\
TOTAL & $\mathbf{4 6 . 9 2 3 . 5 4 9}$ & $\mathbf{6 2 . 7 1 1 . 0 2 0}$ & $\mathbf{7 2 . 9 3 2 . 7 1 5}$ & $\mathbf{8 3 . 6 1 5 . 8 5 2}$ \\
\hline \hline
\end{tabular}

Fonte: STN.

Elaboração do autor.

Também como no Fundef, o FPM e o FPE, depois do ICMS, compuseram duas outras importantes fontes de financiamento do Fundeb. De 2007 a 2010, o crescimento médio para os dois primeiros correspondeu a aproximadamente $52,5 \%$.

A Tabela 7, que evidencia a participação de cada uma das receitas do Fundeb na sua composição, revela que o ICMS foi seguido ao longe pelo FPM e FPE.

Tabela 7: Receitas anuais do Fundeb, segundo as fontes de recursos (\%), de 2007 a 2010

\begin{tabular}{c|c|c|c|cc}
\hline \hline & $\mathbf{2 0 0 7}$ & $\mathbf{2 0 0 8}$ & $\mathbf{2 0 0 9}$ & $\mathbf{2 0 1 0}$ \\
\hline \hline ITR & 0,02 & 0,04 & 0,08 & 0,10 \\
LC n' 87/1996 & 0,70 & 0,60 & 0,50 & 0,50 \\
ITCMD & 0,10 & 0,30 & 0,50 & 0,60 \\
IPI-exp. & 1,10 & 1,00 & 0,80 & 0,90 \\
IPVA & 1,80 & 3,50 & 5,40 & 5,00 \\
Comp. União & 4,30 & 5,00 & 7,00 & 6,40 \\
FPE & 13,58 & 13,50 & 12,40 & 11,70 \\
FPM & 14,30 & 14,10 & 13,00 & 12,20 \\
ICMS & 64,10 & 61,96 & 60.32 & 62,60 \\
TOTAL & $\mathbf{1 0 0}$ & $\mathbf{1 0 0}$ & $\mathbf{1 0 0}$ & $\mathbf{1 0 0}$ \\
\hline \hline
\end{tabular}

Fonte: STN.

Elaboração do autor.

De 2007 a 2010, os recursos, no Fundeb, em termos percentuais, superaram o crescimento das matrículas, o que representou ganhos, ainda insuficientes, para o financiamento da educação básica, graças à elevação dos percentuais das fontes de recursos que compunham o Fundef e inserção de outras novas - as quais apresentaram baixa participação, quando comparadas com o montante total de verbas associadas ao Fundo -, bem como crescimento para a complementação da União.

A Tabela 8 mostra os estados contemplados com a complementação da União, no Fundeb, de 2007 a 2010. A elevação dos recursos, até alcançar o percentual de $10 \%$, em 2010, permitiu o aumento das verbas nos estados e a inserção de dois outros, ou seja, o Amapá (2009) e o Rio Grande do Norte (2010), que até então não haviam entrado na lista desde a implantação do Fundef. 
Tabela 8: Complementação da União ( $\mathrm{R}$ \$ milhões), a preços correntes (nominais), aos estados que não alcançaram o mínimo definido para o valor aluno/ano, de 2007 a 2010

\begin{tabular}{|c|c|c|c|c|c|c|c|c|}
\hline & \multicolumn{8}{|c|}{ Complementação da União (FUNDEB) } \\
\hline & $\begin{array}{c}2007 \\
\text { R\$ milhões } \\
\text { (b) }\end{array}$ & $\begin{array}{c}(\mathbf{b}) /(\mathbf{a}) \\
(\%)\end{array}$ & $\begin{array}{c}2008 \\
\text { R\$ milhões } \\
\text { (c) }\end{array}$ & $\begin{array}{c}(\mathbf{c}) /(\mathbf{a}) \\
(\%)\end{array}$ & $\begin{array}{c}2009 \\
\text { R\$ milhões } \\
\text { (d) }\end{array}$ & $\begin{array}{c}(\mathbf{d}) /(\mathbf{a}) \\
(\%)\end{array}$ & $\begin{array}{c}2010 \\
\text { R\$ milhões } \\
\text { (e) }\end{array}$ & $\begin{array}{c}(\mathbf{e}) /(\mathbf{a}) \\
(\%)\end{array}$ \\
\hline Alagoas & 76,8 & $\overline{3,8}$ & $\overline{97,3}$ & $\overline{3,1}$ & 269,1 & $\overline{5,3}$ & 355,8 & $\overline{4,5}$ \\
\hline Amapá & - & - & - & - & 108,3 & 2,1 & 182,0 & 2,3 \\
\hline Bahia & 472,3 & 23,5 & 775,0 & 24,4 & $1.333,8$ & 26,3 & $1.993,3$ & 25,0 \\
\hline Ceará & 308,4 & 15,3 & 440,1 & 13,9 & 622,8 & 12,3 & 996,2 & 12,5 \\
\hline Maranhão & 558,9 & 27,8 & 790,0 & 24,9 & $1.128,2$ & 22,3 & $1.651,6$ & 20,8 \\
\hline Pará & 490,9 & 24,4 & 801,9 & 25,2 & $1.020,5$ & 20,1 & $1.629,9$ & 20,5 \\
\hline Paraíba & 4,9 & 0,2 & 3,3 & $\mathbf{0 , 1}$ & 70,7 & 1,4 & 187,3 & 2,4 \\
\hline Pernambuco & 19,9 & 1,0 & 132,9 & 4,2 & 282,1 & 5,6 & 528,8 & 6,7 \\
\hline Piauí & 80,3 & 4,0 & 133,8 & 4,2 & 234,6 & 4,6 & 403,7 & 5,1 \\
\hline R. G. do Norte & - & - & - & - & - & - & 17,2 & 0,2 \\
\hline TOTAL & $2.012,4$ & 100,0 & $3.174,3$ & 100,0 & $5.070,1$ & 100,0 & $7.945,8$ & 100,0 \\
\hline
\end{tabular}

Fonte: STN.

Elaboração do autor.

Com a complementação da União concentrada em estados das regiões mais pobres, Nordeste (principalmente) e Norte, evidenciaram-se as disparidades fiscais no território brasileiro, como também mostrou o Fundo anterior. Apenas Bahia, Maranhão e Pará, em 2010, agruparam aproximadamente $66,3 \%$ do total despendido.

O percentual de $10 \%$, conforme a disposição legal, colocado como mínimo, foi estabelecido como ponto de partida para que pudesse haver a injeção de novos recursos, o que permitiria a construção de critérios para aproximar os gastos de um Custo Aluno Qualidade (CAQ) - ainda distante -, definido anualmente.

Ao se estabelecer a soma total dos recursos do Fundeb, inclusive depois de acrescentados os $10 \%$ da complementação da União, que poderiam ser distribuídos aos Fundos por meio de programas com a função de melhorar a qualidade da educação básica, proceder-se-ia à definição do valor mínimo aluno/ano. Na EC n ${ }^{\circ} 53 / 2006$, para o ensino fundamental, em 2007, o índice não poderia ser inferior ao menor valor estabelecido nacionalmente pelo Fundef, em 2006 (art. $2^{\circ}$ ).

O valor mínimo aluno/ano para todo o país, na Lei no 11.494/2007 foi associado às séries iniciais do ensino fundamental urbano, que recebeu fator de ponderação igual a 1,0. Para os demais níveis, modalidades e tipos de estabelecimento de ensino presenciais, os índices variaram de 0,70 a 1,30 (art. $10, \S \S 1^{\circ}$ e $2^{\circ}$ ), respeitando o limite de $15 \%$ para a apropriação dos recursos das matrículas da EJA nos respectivos Fundos (art. 11).

De acordo com o Quadro 3, os fatores de ponderação para os níveis, modalidades e tipos de estabelecimento de ensino no Fundeb, de 2007 a 2010, corresponderam a: 
Quadro 3: Fatores de ponderação e valor aluno/ano associados aos níveis, modalidades e tipos de estabelecimento de ensino para o Fundeb, de 2007 a 2010

\begin{tabular}{|c|c|c|c|c|c|}
\hline \multicolumn{6}{|c|}{ FUNDEB } \\
\hline Etapas, Modalidades e Tipos de Estabelecimento de Ensino & Fatores de Ponderação & \multicolumn{4}{|c|}{ Valor Aluno/Ano ${ }^{1}$} \\
\hline Educação Infantil & & 2007 & 2008 & 2009 & 2010 \\
\hline Creche Integral & $0,80 / 1,10^{\mathrm{a}}$ & 757,79 & $1.245,58$ & $1.485,10$ & $1.556,33$ \\
\hline Creche Parcial & 0,80 & 757,79 & 905,87 & $1.080,07$ & $1.131,88$ \\
\hline Pré-Escola Integral & $0,90 / 1,15^{\mathrm{b}} / 1,20^{\mathrm{c}} / 1,25^{\mathrm{d}}$ & 852,52 & $1.302,20$ & $1.620,11$ & $1.768,56$ \\
\hline Pré-Escola Parcial & $0,90 / 1,00^{\mathrm{e}}$ & 852,52 & $1.019,11$ & $1.350,09$ & $1.414,85$ \\
\hline \multicolumn{6}{|l|}{ Ensino Fundamental } \\
\hline Séries Iniciais (Urbano) & 1,00 & 947,24 & $1.132,34$ & $1.350,09$ & $1.414,85$ \\
\hline Séries Iniciais (Rural) & $1,05 / 1,15^{\mathrm{d}}$ & 994,60 & $1.188,96$ & $1.417,60$ & $1.627,08$ \\
\hline Séries Finais (Urbano) & 1,10 & $1.041,96$ & $1.245,58$ & $1.485,10$ & $1.556,33$ \\
\hline Séries Finais (Rural) & $1,15 / 1,2^{\mathrm{d}}$ & $1.089,32$ & $1.302,20$ & $1.552,60$ & $1.697,82$ \\
\hline Tempo Integral & 1,25 & $1.184,05$ & $1.415,43$ & $1.687,61$ & $1.768,56$ \\
\hline \multicolumn{6}{|l|}{ Ensino Médio } \\
\hline Urbano & 1,20 & $1.136,69$ & $1.358,81$ & $1.620,11$ & 1.697 .82 \\
\hline Rural & 1,25 & $1.184,05$ & $1.415,43$ & $1.687,61$ & $1.768,56$ \\
\hline Tempo Integral e Integrado à Educação Profissional & 1,30 & $1.231,41$ & $1.472,05$ & $1.755,12$ & $1.839,30$ \\
\hline Educação Especial & 1,20 & $1.136,69$ & $1.358,81$ & $1.620,11$ & $1.697,82$ \\
\hline Educação Indígena e Quilombola & 1,20 & $1.136,69$ & $1.358,81$ & $1.620,11$ & $1.697,82$ \\
\hline \multicolumn{6}{|l|}{ Educação de Jovens e Adultos (EJA) } \\
\hline Avaliação no Processo & $0,70 / 0,80^{\mathrm{d}}$ & 663,07 & 792,64 & $1.080,07$ & $1.131,88$ \\
\hline Integrada à Educação Profissional & $0,70 / 1,00^{\mathrm{e}}$ & 663,07 & 792,64 & $1.350,09$ & $1.414,85$ \\
\hline \multicolumn{6}{|l|}{ Instituições Conveniadas } \\
\hline Creche Integral & $0,95 / 1,10^{\mathrm{d}}$ & - & $1.075,73$ & $1.282,59$ & $1.556,33$ \\
\hline Creche Parcial & 0,80 & - & 905,87 & $1.080,07$ & 1.131 .88 \\
\hline Pré-Escola Integral & $1,20 / 1,25^{\mathrm{d}}$ & - & - & $1.620,11$ & $1.768,56$ \\
\hline Pré-Escola Parcial & 1,00 & - & - & $1.350,09$ & 1.414 .85 \\
\hline
\end{tabular}

(1) Os valores, de 2007 a 2010, corresponderam às estimativas publicadas pelas portarias do MEC, disponibilizadas no endereço eletrônico do FNDE.

(a) A partir de 2008; (b) referente a 2008; (c) referente a 2009; (d) referente a 2010; (e) referente a 2009 e 2010.

Fonte: FNDE.

Elaboração do autor.

Os baixos índices estabelecidos para os fatores de ponderação relacionados à educação infantil (creches e pré-escolas, públicas ou conveniadas) e EJA, foram destacados por autores como Monlevade (2007) e Pinto (2009). No caso da primeira, pelo menos até 2010, criou-se uma diferença de gasto, pois os custos para a educação infantil são os mais elevados e não deveriam ser comparados com o ensino fundamental; para a segunda, continuou-se a desfavorecer parcela da população que, tradicionalmente, tem sido excluída das instituições educacionais de ensino.

No período de 2007 a 2010, as distorções foram parcialmente corrigidas com as séries de modificações nos fatores de ponderações relacionados à educação infantil (creche integral, pré-escola integral e parcial públicas, creche e pré-escola integrais conveniadas), além daquelas associadas à EJA (avaliação no processo e integrada à educação profissional). As escolas rurais que atenderam ao ensino fundamental (séries iniciais e finais), também tiveram elevados seus índices no período delimitado.

As políticas de Fundos contábeis, Fundef e Fundeb, aumentaram de maneira importante, o valor mínimo aluno/ano definido para todo o país. Em 1997, correspondeu a $\mathrm{R} \$ 300,00$, para o ensino fundamental público, já no ano de 2010 , chegou a $\mathrm{R} \$ 1.414,85$ para as séries iniciais do ensino fundamental urbano, tendo sido elevado, em média, aproximadamente $371,6 \%$. Caso tivesse seguido os reajustes propostos pelo Índice Nacional de Preços ao Consumidor (INPC), o custo teria alcançado R $\$$ 693,08, ou seja, menos da metade do que foi gasto.

Pelo menos no período observado, a progressiva elevação da complementação da União, até alcançar 10\% do total dos Fundos, em 2010, permitiu diminuir também as 
desigualdades interestaduais. Mas esses ganhos devem se constituir como ponto de partida para a efetiva consolidação da qualidade educacional na educação básica pública no país, o que necessariamente exige, também, a inserção de novos recursos.

Em 2007, a diferença entre o maior e o menor valor aluno/ano para as séries iniciais do ensino fundamental urbano, segundo dados do FNDE, atingiu aproximadamente 195,9\%, ou seja, correspondeu a $\mathrm{R} \$ 757,79$ para os estados que receberam a complementação, e a $\mathrm{R} \$$ $2.242,56$ em Roraima. No ano de 2010, a queda dessa diferença foi expressiva $(88,4 \%)$, alcançando $\mathrm{R} \$ 1.414,85$, nos primeiros, e R $\$ 2.664,97$, no segundo.

No entanto, apesar dos avanços, ainda permaneceram grandes desigualdades interestaduais no financiamento da educação básica e sua universalização, fora o fato de estar relativamente distante a associação entre recursos educacionais e qualidade no processo de ensino e aprendizagem.

\section{Considerações Finais}

A ampliação das responsabilidades municipais para com o ensino fundamental público, durante o Fundef, de acordo com as determinações legais, foi suprida mais pelas transferências vinculadas de recursos, do que pela ampliação do esforço fiscal da grande maioria dos municípios.

Pelas políticas de Fundos contábeis, estabeleceram-se a lógica das perdas e dos ganhos de recursos para os estados e municípios. Mesmo que milhares de governos municipais tenham perdido recursos, tanto com o Fundef quanto com o Fundeb, a proporção dos ganhos quando comparada com o número de matrículas evidenciaram que a maior parte das mesmas foi beneficiada, ainda que distante da qualidade educacional.

O processo se tornou possível, porque a lógica de redistribuição do Fundef e também do Fundeb privilegiaram os locais com maior número de matrículas, que corresponderam aos municípios de médio e grande porte. Assim, contrariaram-se os mecanismos que caracterizaram a distribuição dos recursos do FPM, que beneficiaram municípios de pequeno porte, com verbas insuficientes para garantir melhorias significativas, por exemplo, nas políticas sociais desses governos.

Mesmo depois da promulgação da CF/1988 e da aprovação da LDB/1996, práticas lesivas ao financiamento da educação básica pública continuaram a ocorrer, como no caso da sonegação de impostos, do desvio de recursos e da não aplicação do mínimo disposto legalmente para a MDE (a exemplo da inclusão do salário-educação e do pagamento de inativos), entre outros.

Os ganhos com o Fundef, para o financiamento do ensino fundamental público, e depois para a educação básica, com o Fundeb, que melhoraram a transparência na arrecadação, gestão e investimento dos recursos públicos educacionais, bem como as responsabilidades dos entes federados para com os níveis, modalidades e tipos de estabelecimento de ensino, não foram suficientes para elevar substancialmente o baixo regime de colaboração entre os entes federados no país e permitir a constituição de um Sistema Nacional de Educação.

Em ambos os Fundos, a complementação da União, principal instrumento para tentar reduzir as desigualdades interestaduais no financiamento da educação pública (fundamental e depois básica, com a incorporação de instituiçõos privadas), mostrou-se insuficiente. Em volume de recursos, o Fundeb estabeleceu, a partir de 2010, seu valor como o mínimo de $10 \%$ do total de verbas disponibilizadas pelos governos subnacionais, o que representou ampliação importante em relação ao Fundef. 
No entanto, a disposição legal contida no Fundef possibilitava maior destinação de recursos, referente ao cálculo para a complementação da União, que não foi cumprido em nenhum dos anos de vigência do Fundo, o qual teria atingido índices não inferiores a 15\% do total de recursos despendidos pelos governos subnacionais.

A descaracterização da constituição essencialmente pública do Fundo mereceu destaque, ao incluir matrículas de instituições comunitárias, confessionais ou filantrópicas associadas à educação infantil (creches e pré-escolas, inclusive para a educação especial). Há a necessidade da retirada das matrículas associadas a essas instituições privadas dos recursos do Fundeb, mas sem prejudicar as matrículas da educação infantil, que ainda precisam de novas vagas para atender à demanda, mediante o efetivo compromisso dos entes federados.

A Lei $\mathrm{n}^{\circ}$ 11.494/2007 não se comprometeu com metas de qualidade educacional para toda a educação básica. Além da injeção de novos recursos para a educação, há a necessidade, principalmente, de uma transformação cultural que leve à valorização educacional por toda a população brasileira, no sentido de buscar novos rumos para a formação humana, almejando significativas mudanças sociais.

\section{Referências}

ARAÚJO, Raimundo Luiz Silva. Financiamento da educação básica no governo Lula: elementos de ruptura e continuidade. 182 p. Dissertação (Curso de Pós-Graduação em Educação) -

Universidade de Brasília, Brasília, 2007. Disponível em: <http://bdtd.ibict.br>. Acesso em: 25 mai. 2011.

ARELARO, Lisete Regina Gomes. Financiamento e qualidade da educação brasileira: algumas reflexões sobre o documento "Balanço do primeiro ano do Fundef" - relatório MEC. In: DOURADO, Luiz Fernandes. Financiamento da educação básica. Campinas, SP: Autores Associados; Goiânia. GO: Editora da UFG, 1999, p. 27-46.

ARRETCHE, Marta Teresa da Silva. Federalismo e relações intergovernamentais no Brasil: a reforma de programas sociais. Dados, vol. 45, $\mathrm{n}^{\circ}$ 3, Rio de Janeiro, 2002, p. 431 a 458. Disponível em: <http://dx.doi.org/10.1590/S0011-52582002000300004>. Acesso em: 05 jun. 2011.

BRASIL. Constituição da República Federativa do Brasil de 1988. Brasília, DF: Presidência da República, 2008, 413p.

. Constituição (1988). Emenda Constitucional no 14, de 12 de setembro de 1996. Modifica os arts. 34, 208, 211 e 212 da Constituição Federal e dá nova redação ao art. 60 do Ato das Disposições constitucionais Transitórias. Brasília, DF: Presidência da República, 2012.

Lei $\mathrm{n}^{0}$ 9.394, de 20 de dezembro de 1996. Estabelece as diretrizes e bases da educação nacional. Brasília, DF: Presidência da República, 2011, 31p.

Lei $\mathbf{n}^{0}$ 9.424, de 24 de dezembro de 1996. Dispõe sobre o Fundo de Manutenção e Desenvolvimento do Ensino Fundamental e de Valorização do Magistério, na forma prevista no art. 60, $\S 7^{\circ}$, do Ato das Disposições Constitucionais Transitórias, e dá outras providências. Brasília, DF: Presidência da República, 2011.

Decreto $\mathbf{n}^{\circ}$ 2.264, de 27 de junho de 1997. Regulamenta a Lei no 9.424, de 24 de dezembro de 1996, no âmbito federal, e determina outras providências. Brasília, DF: Presidência da República, 2012.

. Constituição (1988). Proposta de Emenda Constitucional nº 536, de 14 de outubro de 1997. Modifica o artigo 60 do Ato das Disposições Constitucionais Transitórias. Brasília, DF: Câmara dos Deputados, 2012.

. Constituição (1988). Proposta de Emenda Constitucional no 415, de 16 de junho de 2005.

Dá nova redação ao $\S 5^{\circ}$ do art. 212 da Constituição Federal e ao art. 60 do Ato das Disposições Constitucionais Transitórias. Brasília, DF: Câmara dos Deputados, 2012. 
Constituição (1988). Emenda Constitucional no 53, de 19 de dezembro de 2006. Dá nova redação aos arts. $7^{\circ}, 23,30,206,208,211$ e 212 da Constituição Federal e ao art. 60 do Ato das Disposições Constitucionais Transitórias. Brasília, DF: Presidência da República, 2011.

. Medida Provisória no 339, de 28 de dezembro de 2006. Regulamenta o art. 60 do Ato das Disposições Constitucionais Transitórias e dá outras providências. Brasília, DF: Presidência da República, 2012.

Lei no 11.494, de 20 de junho de 2007. Regulamenta o Fundo de Manutenção e

Desenvolvimento da Educação Básica e de Valorização dos Profissionais da Educação - FUNDEB, de que trata o art. 60 do Ato das Disposições Constitucionais Transitórias; altera a Lei no 10.195 , de 14 de fevereiro de 2001; revoga dispositivos das Leis $n^{\text {os }} 9.424$, de 24 de dezembro de 1996, 10.880, de 9 de junho de 2004, e 10.845, de 5 de março de 2004; e dá outras providências. Brasília, DF: Presidência da República, 2011.

BORGES, Vander Oliveira. Fundo de Manutenção e Desenvolvimento da Educação Básica e de Valorização dos Profissionais da Educação - FUNDEB: impactos financeiros junto aos governos estaduais e municipais, nos primeiros cinco anos da sua implantação. 185 p. Dissertação (Curso de Pós-Graduação em Educação) - Universidade de Brasília, Brasília, 2007.

CALLEGARI, Cesar. O FUNDEF e a municipalização do Ensino Fundamental no Estado de São Paulo. São Paulo: Aquariana, 2002, 124p.

. FUNDEB: financiamento da educação pública no Estado de São Paulo. São Paulo: Ground: APEOESP, 2008, 583p.

CASTRO, Jorge Abrahão; DUARTE, Bruno de Carvalho. Descentralização da educação pública no Brasil: trajetória dos gastos e das matrículas. Instituto de Pesquisa Econômica Aplicada - IPEA, Texto para Discussão $\mathrm{n}^{\circ}$ 1.352, Brasília, p. 01-37, 2008. Disponível em:

$<$ www.ipea.gov.br/portal/index.php?option=com content...>. Acesso em: 15 ago. 2011.

DAVIES, Nicholas. O Fundef e as verbas da educação. São Paulo: Xamã, 2001, 151p.

2008, 152p.

FUNDEB: a redenção da educação básica. Campinas, SP: Autores Associados,

FERRAZ, Anna Cândida da Cunha. A transição constitucional e o ato das disposições constitucionais transitórias da Constituição de 05.10.1988. Revista dos Tribunais, nº 26, São Paulo, jan./mar. 1999, p. 54-68.

GOMES, Sandra Cristina. Políticas nacionais e implementação subnacional: uma revisão da descentralização pós-Fundef. Dados, vol. 52, no 3, Rio de Janeiro, 2009, p. 659-690. Disponível em: <http://dx.doi.org/10.1590/S0011-52582009000300004>. Acesso em: 05 jan. 2011.

KOLSLINSKI, Mariane Campelo. O processo de implementação de políticas sociais

descentralizadas: o estudo do FUNDEF. 220 p. Dissertação (Curso de Pós-Graduação em Educação)

- Universidade Estadual de Campinas, Campinas, 2000.

MARTINS, Paulo de Sena. O financiamento da educação básica por meio de fundos contábeis: estratégia políticas para a equidade, a autonomia e o regime de colaboração entre os entes federados. 338 p. Tese (Curso de Pós-Graduação em Educação) - Universidade de Brasília, Brasília, 2009.

MELCHIOR, José Carlos de Araújo. Mudanças no financiamento da educação no Brasil - Coleção polêmicas do nosso tempo; v. 57. Campinas/SP: Autores Associados, 1997, 92p.

MENEZES, Janaína Specht da Silva. O financiamento da educação no Brasil: o FUNDEF a partir dos relatos de seus idealizadores. 310 p. Tese (Curso de Pós-Graduação em Educação) - Pontifícia Universidade Católica do Rio Grande do Sul, Porto Alegre, 2005.

MONLEVADE, João Antônio. Para entender o FUNDEB. Ceilândia: Idéa, 2007, 144p.

MONLEVADE, João Antônio; FERREIRA, Eduardo. O FUNDEF e seus pecados capitais: análise do Fundo, suas implicações positivas e negativas e estratégias de superação de seus limites. Ceilândia, DF: Idéa Editora, 1997, 96p.

OLIVEIRA, Ramon. Os limites do FUNDEB no financiamento do ensino médio. Currículo sem fronteiras, vol. 08, $\mathrm{n}^{\circ}$. 2, p. 78-96, Jul./Dez. 2008. Disponível em:

<www.curriculosemfronteiras.org/vol8iss2articles/oliveira-r.pdf>. Acesso em: 05 jan. 2011. 
OLIVEIRA, Romualdo Portela de. O direito à educação. In: Oliveira, Romualdo Portela de; ADRIÃO, Theresa (Orgs.). Gestão, financiamento e direito à educação: análise da LDB e da Constituição Federal. São Paulo: Xamã, 2001, p. 15-43.

OLIVEIRA, Rosimar de Fátima. Do Fundef ao Fundeb: o processo político de formulação da Emenda Constitucional $n^{\circ}$ 53/2006. Jornal de Políticas Educacionais, no 5, jan./jun. 2009, p. 50-58.

Disponível em: 〈www.jpe.ufpr.br/n5_5.pdf>. Acesso em: 05 jan. 2011.

PINTO, José Marcelino de Rezende. Um Fundinho chamado "Fundão". In: DOURADO, Luiz

Fernandes. Financiamento da educação básica. Campinas, SP: Autores Associados; Goiânia. GO: Editora da UFG, 1999, p. 85-98.

25, nº 2, Porto Alegre, mai./ago. 2009, p. 323-340. Disponível em: <seer.ufrgs.br/rbpae/article/download/19500/11324>. Acesso em: 30 out. 2011.

PINTO, José Marcelino de Rezende; ADRIÃO, Theresa. Noções Gerais sobre o financiamento da educação no Brasil. Eccos - Revista Científica, vol. 8, no 1, São Paulo, jan./jun. 2006, p.23-46.

Disponível em: <redalyc.uaemex.mx/src/inicio/ArtPdfRed.jsp?iCve=71580102 >. Acesso em: 30 out. 2010.

ROCHA, Carmen Lúcia Antunes Rocha. Natureza e eficácia das disposições constitucionais transitórias. In: GRAU, Eros Roberto; GUERRA FILHO, Willis Santiago (Org.). Direito constitucional: estudos em homenagem a Paulo Bonavides. São Paulo: Malheiros, 2001, 558p. SANTOS, Bruno Ricardo Viana Sadeck dos. Aspectos do federalismo brasileiro: o caso do Fundo de Manutenção e Desenvolvimento do Ensino Fundamental e Valorização do Magistério. 153 p. Dissertação (Curso de Pós-Graduação em Ciência Política) - Universidade de Brasília, Brasília, 2006. Disponível em: 〈http://bdtd.ibict.br〉. Acesso em: 10 out. 2010.

SAVIANI, Dermeval. Política e educação no Brasil: o papel do Congresso Nacional na legislação do ensino. Campinas, SP: Autores Associados, 1999. - (Coleção educação contemporânea), 158p. SILVA, José Afonso da. Comentário contextual à Constituição. 6. ed. São Paulo: Malheiros, 2009, $1023 \mathrm{p}$.

SOUSA, Luiz. Fundeb: avanços, limites e perspectivas. Eccos - Revista Científica, vol. 8, $\mathrm{n}^{\circ}$ 2, São Paulo, out. 2006, p. 275-290. Disponível em:

<redalyc.uaemex.mx/src/inicio/ArtPdfRed.jsp?iCve=71580202>. Acesso em: 30 abr. 2010.

TORRES, David et al. Revelando o Sistema Tributário Brasileiro. São Paulo: Edições SINAFRESP, 2003, 555p.

VAZQUEZ, Daniel Arias. Educação, descentralização e desequilíbrios regionais: os impactos do Fundef. 186 p. Dissertação (Curso de Pós-Graduação em Economia) - Universidade Estadual de Campinas, Campinas, 2003.

Notas

\footnotetext{
${ }^{1}$ Doutorando em Educação pela USP. A pesquisa contou com o apoio financeiro da CAPES. Email do autor: fabiolucianocosta@usp.br

${ }^{2}$ Segundo o texto original do art. 60 do ADCT, o Poder Público, nos dez primeiros anos da promulgação da $\mathrm{CF} / 1988$, deveria aplicar pelo menos 50\% dos recursos vinculados à educação para "eliminar o analfabetismo e universalizar o ensino fundamental".

${ }^{3} \mathrm{O}$ autor conclui que, em sua opinião, o Fundef e o Fundeb estariam mais bem dispostos no texto permanente da CF/1988, no sentido de tentar melhor estabelecer a cooperação e solidariedade entre os entes federados.

${ }^{4}$ De 1996 a 2008, com o FSE, Fundo de Estabilização Fiscal (FEF) e a Desvinculação das Receitas da União (DRU), esse valor correspondeu a 4,32\% (menos $20 \%$ de 5,4\%) e, de 1994 a 1996, atingiu 7,2\% (menos 20\% de 9\%), antes da modificação da CF/1988 (art. 60 do ADCT). Em 2009, os valores legais corresponderam respectivamente a $4,86 \%$ (incluídos os $10 \%$ para a DRU); em 2010, a 5,13\% (5\% para a DRU); somente em 2011, foi extinta a DRU para a educação. Em valores nominais, de 1994 a 2007, os prejuízos para a educação com as desvinculações chegaram a aproximadamente R $\$ 50$ bilhões (DAVIES, 2008).

${ }^{5}$ Neste trabalho, na parte relacionada às fontes de recursos tanto para o Fundef quanto para o Fundeb, não serão apresentados os dados fiscais para essa contribuição social.
}

Recebido:Junho-2012 
Aprovado: Novembro-2012 